\title{
AN EXPERIMENTAL STUDY OF CHRONIC AORTIC REGURGITATION IN DOGS
}

\author{
By H. C. BAZETT AND JANE SANDS \\ ASSISTED BY J. M. BEFreI
}

(From the Department of Physiology, University of Pennsylvania)

(Received for publication June 17, 1926)

\section{INTRODUCTION}

The present experiments were undertaken in an attempt to determine the progress of heart dilatation or hypertrophy, when the aortic cusps had been damaged, under conditions where there was no infection and where myocarditis could therefore be excluded. In some animals of our series infection occurred accidentally, but as a general rule there was no evidence of such a complication. Before and after operation the condition of the animal was determined by $\mathrm{x}$-ray and electrocardiographic examination, and in addition, in some animals, tests were made to determine the capacity for work. The animals were kept for periods varying from 2 to 11 months.

No new principle was introduced in the above experiments, which differed from those of earlier workers merely in details, and in the use of modern methods. Cohnheim (1) first in 1877 described acute experiments of this type in dogs, perforating the aortic cusps by passing a button-shaped metallic sound down the carotid artery, finding he could destroy 1,2 , or even 3 valves. He noted that in such experiments a murmur, usually whistling in type, was at once heard, the pulse became water hammer in type; the heart compensated for the lesion and was able to maintain normal mean arterial and venous pressures, unless the lesion was too severe, when complete failure and death supervened. He was unable to produce an intermediate degree of damage, with slowly developing heart failure. Rosenbach (2) in 1878 working under Cohnheim's direction elaborated these results and made chronic experiments. Marey (3) in 1881 performed similar operations in horses and demonstrated an abnor- 
mal rise of intraventricular pressure during diastole; the kymograph tracings he reproduced also demonstrated an increase in pulse rate of almost 100 per cent as the result of the lesion. Tangl (4) in 1889 used a similar technic in chronic experiments to investigate heart hypertrophy and concluded that the changes depended on the time and degree of leak and that the number of fibers in such a heart were not increased, but that each individual fiber was larger.

Hasenfeld and Romberg (5) in 1897 repeated such experiments aseptically in both cats and dogs. They observed hypertrophy of the left ventricle uuder these conditions in the absence of sepsis, basing their conclusions on the weights of the different chambers of the heart and on the microscopic diameters of the fibers as compared with the normal. They noted that hypertrophy was present in the left ventricle with some dilatation even with small lesions. With larger leaks these changes were greater and also affected, but to a less extent, the left auricle and right ventricle. They did not explain their evidence for dilatation, but probably they meant an increased heart cavity. They noted also the complete absence of symptoms in the animals unless the lesions were great, when again sudden death was observed. They considered that the hypertrophy was due to the increased work and that it was definitely compensatory, since after its development the animals were able to make a rather better response to experimental aortic constriction than in acute experiments. In their chronic experiments inelasticity and tortuosity of the arteries developed. No striking change of pulse rate was observed.

H. A. Stewart (6) in 1908 introduced the theory that the collapsing pulse of aortic insufficiency depended on peripheral vascular dilatation, rather than on a regurgitation of fluid. He found, however, intraventricular diastolic pressures as high as $40 \mathrm{~mm}$. of $\mathrm{Hg}$ and advanced the hypothesis of a regurgitation of pressure with minimal fluid reflux. His evidence for this rested on heart plethysmographic records following regurgitation, since no increased difference between systolic and diastolic volumes was observed, as might have been expected if there had been much pendulum blood; his conclusions, however, were only warranted if the filling of the right ventricle remained unchanged, and of this he had no evidence. In a later 
paper (7) he examined the effect of chronic lesions on heart hypertrophy and concluded that changes in heart weight began to take place within 5 days. His evidence was poor since it depended entirely on average heart weight to body weight ratios, and his normal animals from which the weight standard was set included dogs as large as 21.85 kilos, while his experimental animals were never above 8.1 kilos in weight. Since it has been shown by G. N. Stewart (8) that the heart weight is not a simple function of body weight in dogs, the sets of figures obtained by $\mathrm{H}$. A. Stewart were not comparable, and such exact deductions as to the day hypertrophy commenced were inadmissible.

MacCallum (9) described in 1906 a special valvulotome (used by H. A. Stewart) and himself made experiments of this type in 1911. He criticised Stewart's hypothesis, and showed a great fall of diastolic pressure in the aorta even when the heart was connected to a reservoir offering a constant peripheral resistance, and where vascular dilatation could not play a part.

Wiggers (10) in 1915 in acute experiments recorded the arterial and ventricular pressure changes photographically, concluding that the fall of aortic pressure during diastole was steeper when the aortic leak was greater, and that the rapid fall of pressure depended therefore on the condition of the valves rather than on peripheral dilatation. In his book on the circulation Wiggers (11) has taken the position that a considerable "regurgitation" of pressure may occur with only minimal back flow of fluid.

Sherrington (12) pointed out that the fall of diastolic pressure with regurgitation is as readily seen in the spinal animal, where all the vessels are already fully dilated, as in the intact animal.

Straub (13) in 1919 discusses the mechanisms of adjustment to aortic regurgitation and gives experimental data from plethysmographic records but without details.

Preliminary reports of our own (14) (15) work have appeared already. Still more recently Herrmann (16) has reported data in dogs kept 2 to 530 days after production of such lesions, where electrocardiographic records were taken, but where heart hypertrophy was estimated only by the relative weights of the two ventricles in comparison with body weight and normal standards. Any definite 
change in the electrocardiograph was only occasionally noted by him. Eyster and Meek (17) originally described the x-ray technic (but in a more exact form) that we have used, and quite recently Eyster (18) has given a preliminary report of results obtained on animals with experimental aortic regurgitation where x-ray evidence of hypertrophy was also obtained.

\section{METHODS}

The dogs employed were those for which figures have already been given in another paper (19) in regard to the effect of anesthesia and other procedures on the duration of the phases of the heart cycle and on heart size, so that some normal standards are available for comparison in each of these animals. The numbering of the animals in the two papers is identical. The technic of obtaining $\mathrm{x}$-ray photographs, electrocardiographs and heart sound records was the same as that there described.'

Before operation the dogs were kept under observation for intervals varying from 3 days to 3 months (more commonly 1 to 2 weeks) and during this time electrocardiographic records and $\mathrm{x}$-rays were taken, in the earlier animals of the series on at least 3 separate days. The electrocardiographic records were obtained on each day first without morphine, then after the full development of the morphine effect, and if any obvious excitement was manifested by the animal without morphine the results were discarded, and records attempted on another day. In a later series of animals, dogs 13 to 16, electrocardiographs were taken without morphine and then morphine was given for obtaining $x$-rays, while in animals 17 to 23 both x-rays and electrocardiographs were obtained under morphine, and also after the vagal action had been paralyzed by an injection of atropine sulphate. After operation exactly the same technic was followed and records obtained for comparison.

The operation was performed under light ether anesthesia. A bullet-shaped metallic stylet (with maximum diameter of $3.5 \mathrm{~mm}$.)

${ }^{1}$ Composite $\mathrm{x}$-ray photographs taken during expiration were used to give the diastolic shadow, as well as some instantaneous exposures of 0.1 to 0.2 second duration; in the latter case the time of the exposure was judged from a simultaneous electrocardiogram. 
was the most satisfactory instrument in our hands, since it produced a considerable hole in the valves, and yet was less liable than a sharper instrument to damage other parts of the heart. As the animals had often been used for 6 or more electrocardiographs, and some 6 to 12 x-rays before operation, the least dangerous method was selected. With such a technic there is a greater chance of healing, and of gradual diminution of the leak by cicatrisation than probably occurs with the use of the valvulotome, or any method that can tear away a whole cusp, but, as will be seen, the lesions usually persisted, and were fairly consistent in size from animal to animal. The operation was usually performed in the x-ray room with assistance from the fluoroscope, which allowed the position of the stylet to be determined more exactly, and enabled the immediate changes in the heart to be observed. Even with this assistance the plunger occasionally caught in the aortic arch simulating the obstruction felt from a valve leaflet, the arch was perforated, and death occurred. At the end of the operation the carotid was ligated. The procedures were found to be easier if a flat table was used and the head of the animal was kept fully extended.

Since autopsies showed that these animals had persistent holes with thickened edges and of a diameter smaller than that of the stylet, a second operation was often performed to stretch the old holes or make new ones, and in most of these cases the other carotid was used (since the first was no longer patent unless the superior thyroid had been left intact). No ill effects were seen from ligature of both carotids in this way.

As Cohnheim (1) noticed, the destruction of one valve cusp is easy, but it is much more difficult to make the stylet catch in a second cusp, since it tends to slip through the first tear. If one needs to damage all three valves, very varying angles of the stylet to the animal must be employed and the stylet must be moved up and down a number of times until three separate obstructions have been met and pierced. During this procedure there are considerable risks, immediate from perforation of some surface not a valve such as the arch of the aorta, and remote from infection due to the prolonged manipulation in the dark, and inevitable bruising of the tissues. The dangers are greater at a second operation when the valvular 
changes have lowered the resistance to infection in the heart and the ligature of both carotids has done the same for the wound. Consequently the mortality of the second operation, was much higher than that of the first. The production of lesions of three valves in a single operation was immediately fatal, with one exception (see experiment $\mathrm{C}$ ). On the other hand by operating in two stages, big lesions of two or three valves were successfully produced in five animals with the production of no marked disability, except in two after the development of infection. Occasionally in the single operation extensive lesions of only two valve cusps were sufficient to cause immediate death.

Since in our experiments large changes in pulse rate have occurred, attempts have been made to exclude this factor as far as possible either by section of both vagi or by atropine injections. The former of these procedures proved disappointing. In one such experiment (experiment $\mathrm{G}$ ) the right vagus was divided just distal to the origin of the recurrent laryngeal within the chest (an operation very kindly performed for us by Dr. Sweet) the left vagus was later divided in the neck and still later regurgitation produced. The autopsy, however, showed an aberrant branch of the right vagus arising above the recurrent laryngeal and passing to the heart. Since recovery from this operation was also complicated in this animal by persistent vomiting, recourse was had to atropine injections and in many instances the actual lesion was itself produced under the effects of atropine.

To test the ability of the animal to do work, and at the same time to increase the probability of the development of a real cardiachypertrophy, some of the dogs were made to exercise on a treadmill. This was built of the same general type as that described by Külbs (20). The treadmill was set at an angle varying between $10^{\circ}$ and $12.5^{\circ}$ and the animals were able to control the amount of work performed. They were tied on the mill for one hour or less, and were left to do what work they chose. The dogs soon learned to steady the machine by leaning against the side, so that they could rest or lie down as desired. Exercise was usually given four or five times a week, and note taken of the distance voluntarily travelled. The climb was calculated from the angle of the tread, and represents approximately the relative amount of work done, since when travelling fast the animal 
maintained its position on the inclined plane by its own movements. No accurate estimation is, however, possible, since at times the animal supported a considerable proportion of its weight by dragging on its collar.

The surviving animals were ultimately killed, generally by chloroform. In a few cases, blood pressures were taken at this time using a Hürthle manometer connected alternately with brachial and femoral arteries in the same way as already described for acute experiments (21).

Immediately after death the heart was removed, drained of blood and weighed; one large cannula was then tied into the aortic arch just above the valves, and a second into the left ventricle, and the volume per minute leaking back into the ventricle from the aorta was then measured, using approximately a pressure of 1 meter of saline $(73 \mathrm{~mm}$. of $\mathrm{Hg}$ ).

In some of the later experiments, after removal of the cannulae and stitching of the ventricular wall, casts were made of the cavities of the right and left ventricles. This was done by the simple method of using a paraffin vaseline mixture setting at about $45^{\circ} \mathrm{C}$., and pouring it into the two ventricular cavities through a short funnel, the heart being held up by the auricles until the two masses had set. Though the cavities are in this way distended at very low pressures, and the actual volumes may be very different from those existing in life, the casts obtained allow a good comparison of the relative volumes of the two sides. Any such comparison is quite valueless if there is some rigor mortis of the heart, since this rarely comes on at the same time in the two sides; immediately after death this error does not arise. In one animal death occurred unexpectedly and the heart was in rigor at autopsy. In this case casts were made after tap water had been perfused through the coronary arteries (with massage) which removes the rigor leaving what appears to be a uniform water turgor. A few control experiments on hearts of normal dogs in rigor mortis indicated that if this procedure were followed comparable casts were obtained from the two ventricles, though no doubt the absolute volume had been altered. Keller (22) has found that, if rigor can be excluded, the casts of the two sides are of equal volume, but his figures demonstrate the immense errors present as soon as rigor mor- 
tis occurs. If proper precautions are taken these errors should be rare. The following table contains figures obtained on four hearts soon after death in normal dogs.

\begin{tabular}{c|c|c|c}
\hline Weight of dog & Weight of heart & Right ventricle & Left ventricle \\
\cline { 2 - 3 } & grams & volume cc. & volume cc. \\
8.5 & 60.5 & 10.0 & 9.7 \\
& 71.0 & 4.5 & 5.2 \\
9.25 & 75.0 & 27.5 & 9.7 \\
13.0 & 106.0 & 22.8 & 23.7 \\
\hline
\end{tabular}

The figures demonstrate only slight variations between the two sides except in the third where commencing rigor was suspected. Three other hearts in full but irregular rigor were perfused with water and gave volumes for the left ventricle in comparison with the right of 100,107 and 97 per cent respectively, showing a remarkably consistent equality. We consider therefore that the method gives a comparison of the two ventricles which will only rarely be deceptive. After a rough macroscopic examination had been made of the heart, it was fixed in formalin and sent to Dr. R. T. Grant of University College, London, who is investigating this material in more detail, and will report his findings independently.

In addition we are indebted to Dr. B. E. Lucké for making some other histological and bacteriological examinations.

\section{EXPERIMENTS}

While 23 dogs have been used in the course of this research, yet two of these were used as controls only and two others died of trauma at the first operation. Of the remaining 19, 2 were killed within 1 to 3 days of the operation in order to determine the early condition, and 11 survived the operation until they were either killed or were operated on a second time. Seven dogs in all had a second operation and of these 2 died on the table from trauma to the aortic arch, 2 died a few days later from septicemia, and 3 survived for months. Two other animals survived the initial operation for a few days, but only one of these appeared to have real decompensation, and it was the only animal in the whole series, that clinically showed any signs 
of progressive failure. These 2 animals will be considered later (experiments $\mathrm{C}$ and $\mathrm{H}$ ). Four animals died on the table at the first operation as the result of the lesion causing too great a regurgitation, or interfering with the coronary circulation.

\section{Experiment $A-D o g 3$}

Male, 10 kilos. Normal electrographic and heart sound records and short exposure $\mathrm{x}$-rays with tube to film distance of $80 \mathrm{~cm}$. were taken before operation, all under morphine. The dates when records were taken can be seen in table 1 .

In this and the succeeding tables the symbols used have the following significance:

$P P=$ duration of the $P$ wave.

$\mathrm{PQ}=$ start of $\mathrm{P}$ to beginning of $\mathrm{Q}$ or $\mathrm{R}$.

$\mathrm{QS}=$ duration of QRS group.

$\mathrm{QT}=$ start of $\mathrm{Q}$ to end of $\mathrm{T}$.

Mechanical systole $=$ interval between the beginning of the first and second heart sounds.

$\mathrm{R}$ to second = peak of the $\mathrm{R}$ wave to the beginning of the second sound.

$\mathrm{T}$ to second = end of the $\mathrm{T}$ wave to the beginning of the second sound. Where the second sound begins before the end of $\mathrm{T}$ these values are negative and are italicized in the table.

$\mathrm{K}, \mathrm{K}^{\prime}, \mathrm{M}$ and $\mathrm{M}^{\prime}$ are factors by which the square root of the cycle must be multiplied to obtain QT, ST, first to second sound, and peak of $\mathrm{R}$ wave to second sound. Any considerable variations in these values indicate a change in the duration of systole not explicable simply on the basis of variations in pulse rate.

The area given for the $x$-ray is measured without correction for tube distance and is expressed in square centimeters. If the exposure has been instantaneous, the columns indicate the relation of the exposure to respiration and to the heart cycle. In the latter case the time is given in $1 / 10$ seconds between the beginning of the exposure and the previous wave of the E.C.G. and between the end of the exposure and the next E.C.G. wave, comparison being made to the peak of $P, R$, $\mathrm{S}$ and the end of $\mathrm{T}$. The pulse rate figures express the average of 4 or 5 cycles previous to the exposure.

January 22, 1923. 2:15 p.m., morphine sulphate, 50 mgm. 2:45 p.m., records of E. C. G. and sounds. 2:55 p.m., chloroform-ether, then pure ether. One cusp ruptured with immediate increase in pulse rate. Fluoroscopic examination showed slight decrease $(1 \mathrm{~mm}$.) in the transverse diameter, and no recognizable change in the longitudinal axis. 3:20 p.m., operation finished-ether discontinued. 3:30 p.m., E. C. G. and sounds. About 3:40 p.m., 2 x-rays with E. C. G. checks, but animal restless, coming out of ether. 4:00 p.m., dog running about room-staggering, but no circulatory deficiency noticed.

January 23, 1923. The dog perfectly fit, good appetite, running and jumping, 


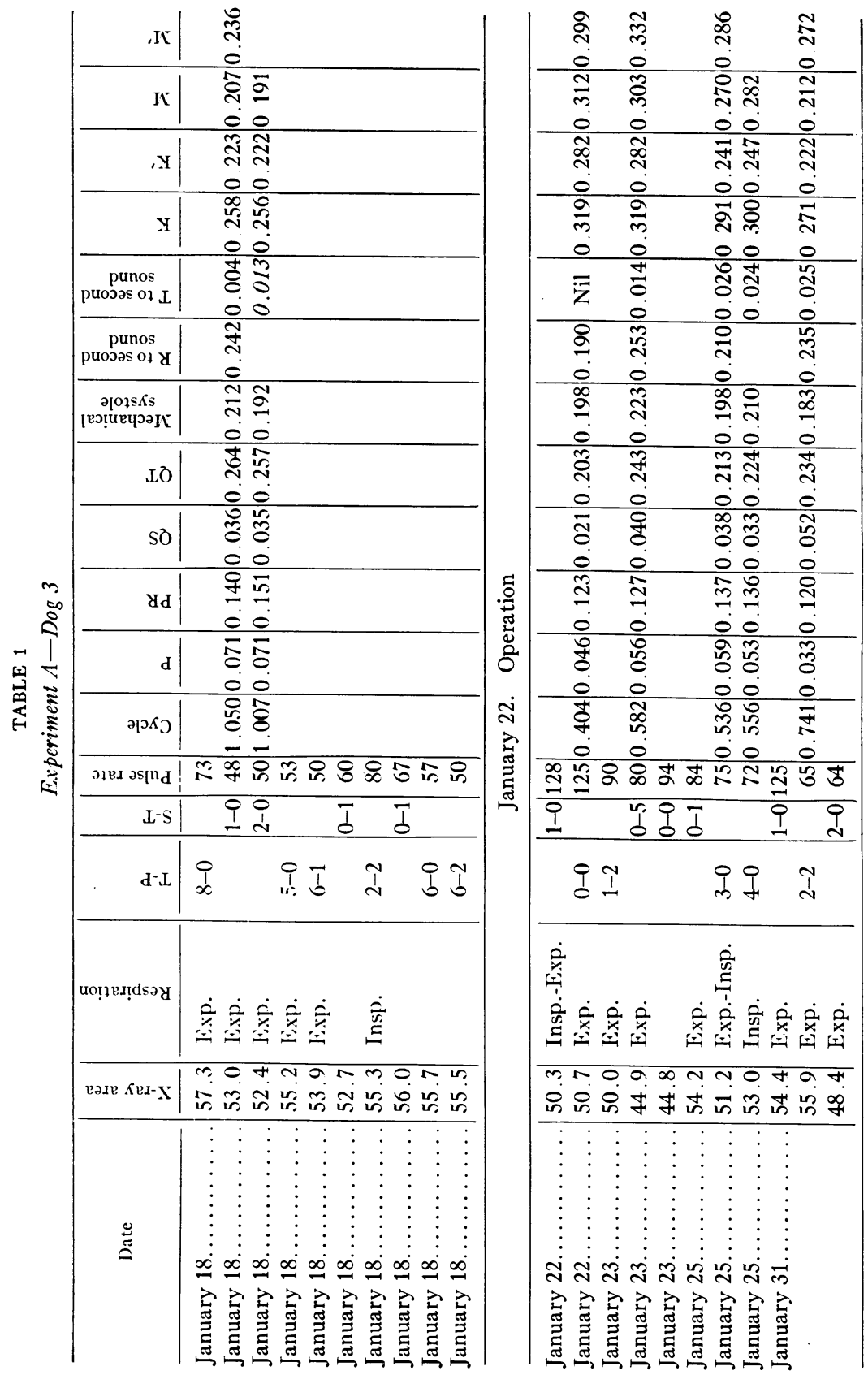




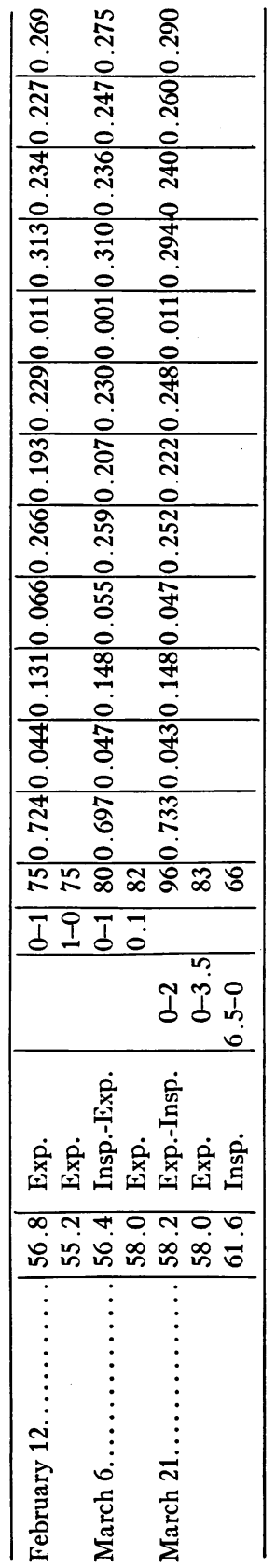


or standing on hind legs, but not quite so excitable as usual. No dyspnea. Extra systoles, probably left ventricular, occasionally present.

January 25, 1923. Exercised in yard for 10 minutes just before records taken. January 26, 1923 . 2:15 p.m., morphine sulphate, 100 mgm. 3:37 p.m., chloroform. 3:51 p.m., blood pressure record from femoral on Hürthle manometer. Pulse rate 89. Pressure 275/75. 3:58 p.m., x-rays and E. C. G. records until death. The changes preceding death have been already given in a previous paper (tables 3 and 7). Sample x-ray photographs are reproduced in figure 1.

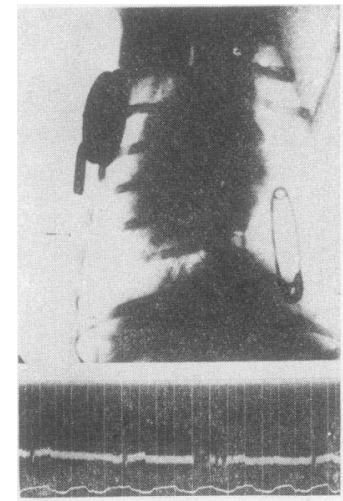

Fig. $1 a$

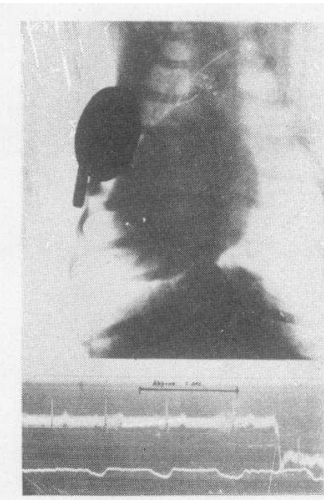

Fig. $1 b$

Fig. 1. Experiment A

a. Before operation, fourth x-ray of January 18 , (see table 1 ).

$b$. Three days after operation, third x-ray of January 25 , table 1 .

Below each $x$-ray is mounted the electrocardiogram taken at the same time, the time of exposure being indicated by the induction currents on the electrical record. Below the electrocardiogram is the respiratory record, the up stroke indicating expiration. Time intervals $\frac{1}{10}$ second.

Autopsy. Heart very distended-pericardium tense. With 1 meter pressure of saline in aorta 2.3 liters per minute leaked into left ventricle. A hole was present in the posterior cusp (about $7 \mathrm{~mm}$. by $3 \mathrm{~mm}$.) close to its attachment. The margins were thickened and rounded. There was also some thickening of the endothelium on the interventricular septum and on the aortic cusp of the mitral valve. Weight of heart 91 grams, i.e., 0.91 per cent of body weight. (The normal ratio according to Herrmann is 0.798 per cent for dogs of varying weights and according to Joseph 0.720 for male dogs of this weight.) The left ventricular wall appeared to be slightly thickened, but the change was not definite. Microscropic examination by Dr. Grant showed the thickening of the edges of the lesion to be due to fibrosis with no indication of active inflammation. We observed 
absolutely no disability from such a lesion of a single cusp, which however gave a very definite water hammer pulse and big pulse pressure, though the pulse rate increase was only moderate. It was also noticeable that immediately after operation and on the following day the heart shadow area was always smaller than in any of the control photographs, while six weeks later shadow areas larger than any of the control values were obtained.

\section{- Experiment B-Dog 15}

Male. Initial weight 10.0 , final 12.25 kilos. Increased weight due to fat. On each day electrocardiograph and heart sound records were taken without morphine, but 40 to $150 \mathrm{mgm}$. of morphine sulphate were given before long composite $\mathrm{x}$-ray exposures in the expiratory position were taken (tube to film distance 1 meter). Dates of records and of operations are indicated in table 2 (see also figs. 2, 3, 4). Exercise on treadmill for 30 to 45 minutes on May 7 and 8, but only travelled 1 kilometer in this time, became short of breath, took frequent rests and vomited afterwards. Exercise tried again on 4 days between May 12 and 18 with similar results. Average work 1.13 kilometer in 37 minutes with "climb" of 194 meters. July 12 to September 9, 1924, exercise repeated during periods separated by a three weeks rest, leaving a total of 28 days work during the whole period. Average distance travelled was 1.45 kilometer with a climb of 253 meters. The animal worked on the average for 49 minutes, but rested for about 19 minutes of this time. Leaving him on the treadmill for 60 to 70 minutes did not increase the work done, as after the first 15 minutes he seemed fatigued and could not be coaxed to do much more work. Occasionally after work especially in warm weather, the dog vomited. During some cold days in the middle of this period the amount of work done was much greater, reaching on one day 4.78 kilometers. Work was done on 14 days during the last month of life with an average distance travelled of 1.09 kilometers and a climb of 190 meters only. The decreased work was coincident with an increased room temperature. Though the power to do work was thus limited, the animal did not appear in any way ill and was as lively as any normal dog.

December 17, 1925. Morphine, $150 \mathrm{mgm}$. Chloroform followed by ether. Right vagus dissected, stimulated and no evidence of regeneration found. Blood pressure by Hürthle manometer. Brachial $121 / 52$ and femoral $137 / 47$, pulse rate 106 . Killed with chloroform.

Autopsy. Pericardium contained 1 or $2 \mathrm{cc}$. of fluid. With 1 meter of water pressure 2.8 liters regurgitation into left ventricle per minute.

The right anterior cusp had a large hole $5 \mathrm{~mm}$. diameter with a small fold which may have acted as a secondary valve to the hole. The left anterior cusp had a hole about $4 \mathrm{~mm}$. diameter. The edges of both holes were thickened. The posterior cusp had an almost healed hole of about $1 \mathrm{~mm}$. diameter only.

The heart was only weighed after regurgitation had been tested, which was by mistake carried out with water instead of saline, so that some water passed into 


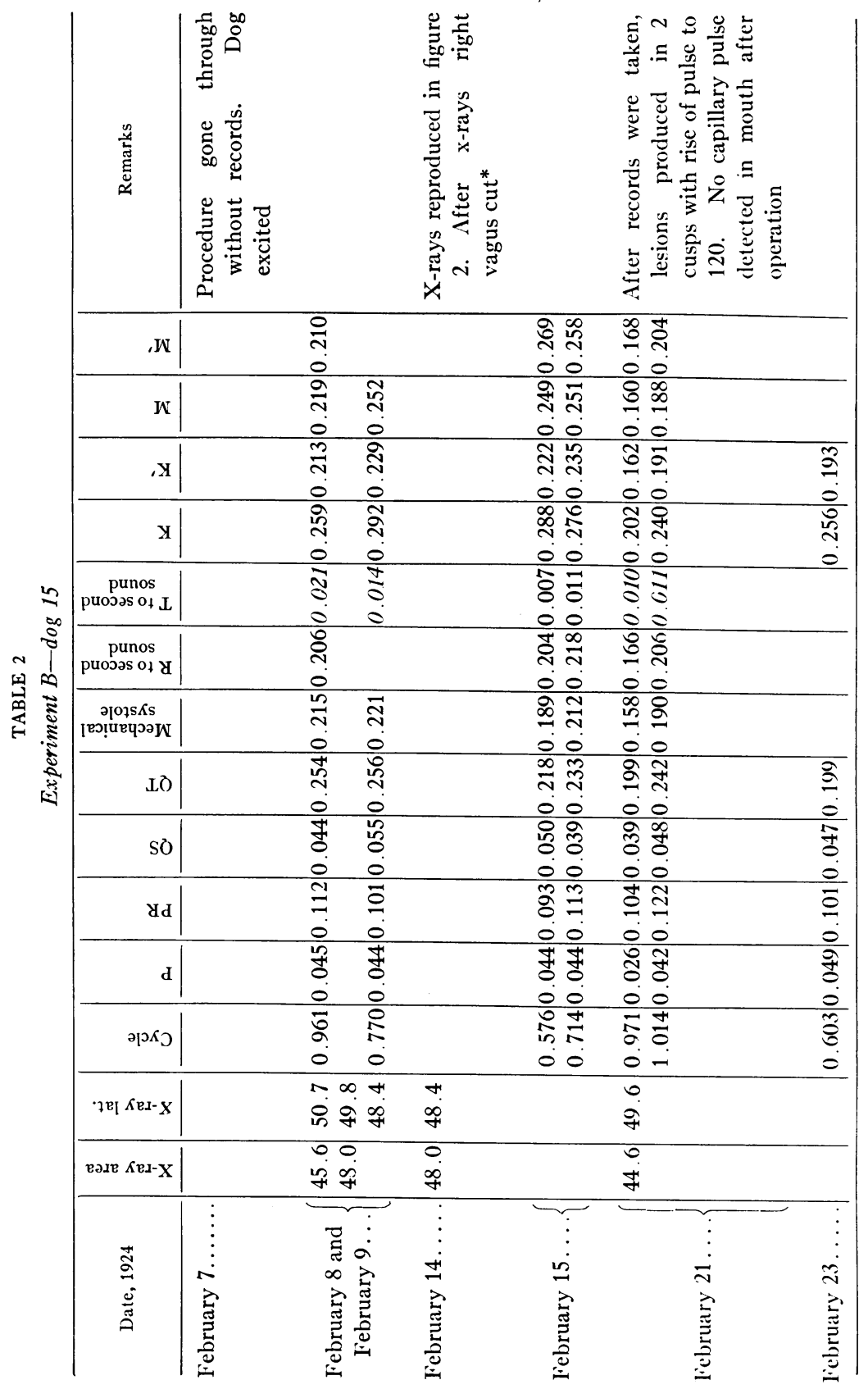


H. C. BAZE'T'T AND JANE SANDS

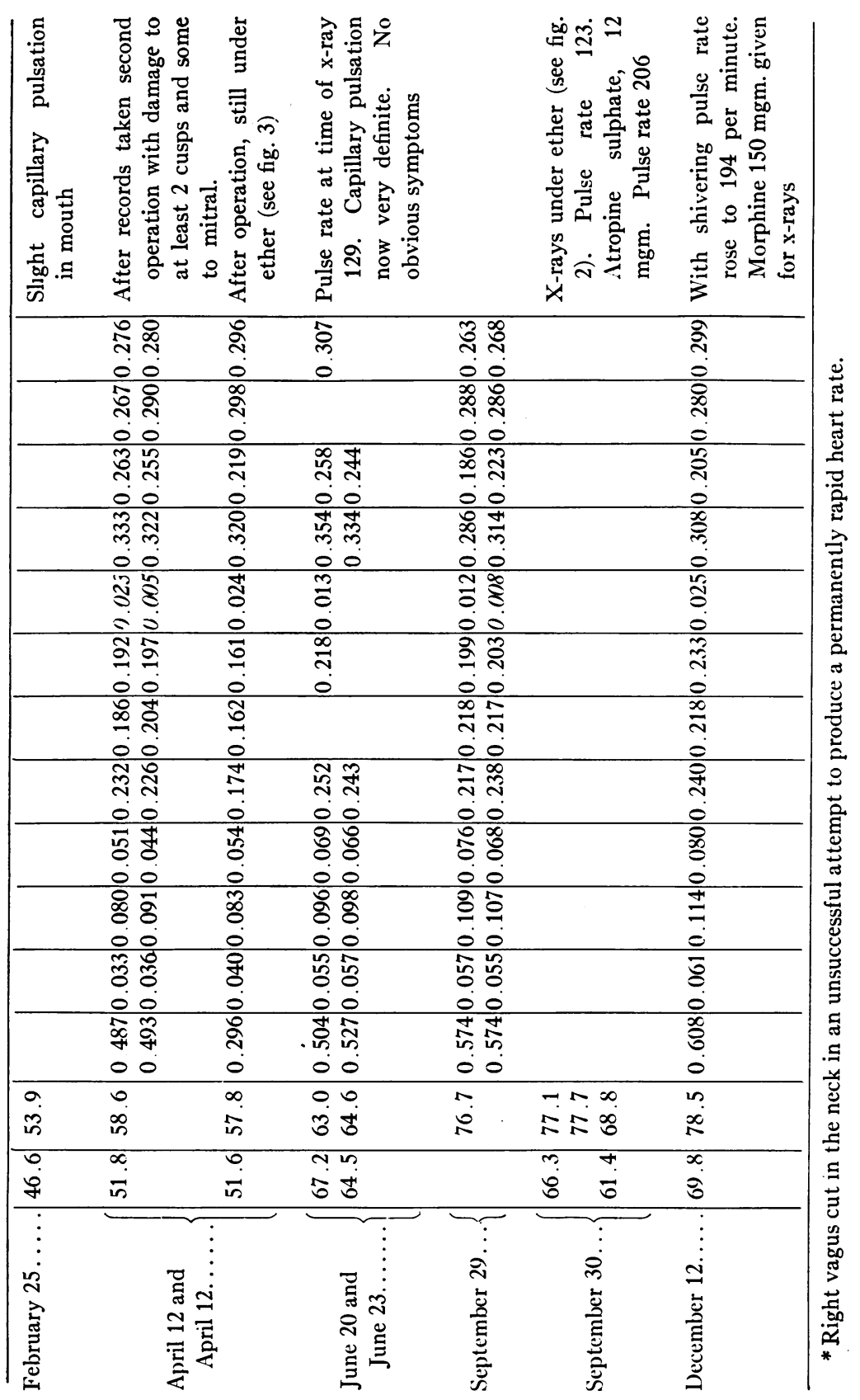


the coronary arteries and some degree of water turgor resulted. The heart then weighed 177 grams and after 9 days in formalin (10 per cent) 164 grams. Controls on several normal hearts treated in a similar way suggested that the real weight of the heart was at least 135 to 145 grams, corresponding therefore to a minimum of 1.1 to 1.2 per cent of the body weight. The left ventricular wall was very

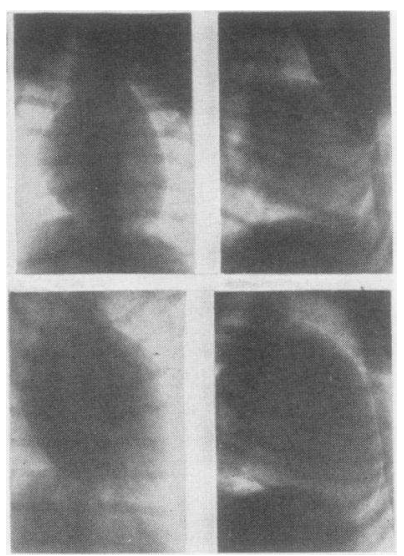

Fig. 2. EXPERIMENT B

Two upper photographs are those taken on February 14, 1924, after morphine injection before any operation; the two lower are the anteroposterior and second lateral taken on September 30, 1924, after morphine and ether. Areas-Anteroposterior 48.0 and 66.3 , lateral 48.4 and 77.7 sq. $\mathrm{cm}$.

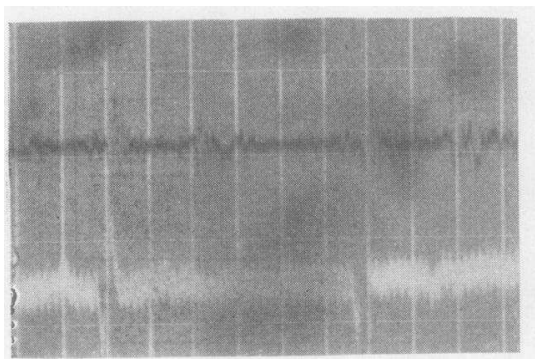

Fig. $3 a$

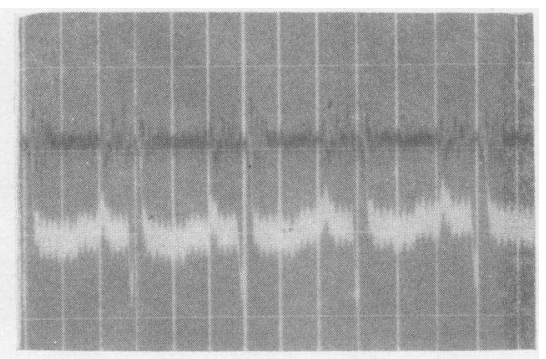

Fig. $3 b$

Fig. 3. EXPERIMENT B

a. Electrocardiogram (white) Lead II and heart sounds (black) taken on April 12 , 1924, when moderate aortic regurgitation was present.

$b$. The same records taken about 30 minutes later after operation with extreme regurgitation, and loud diastolic murmur. 
much thickened, the right was definitely thicker than normal, and the left auricle also thickened. There was no change noted macroscopically in the large arteries.

Casts showed that the left ventricle had a normally shaped conical cavity of 27 cc. volume, while the right had a much elongated spiral shaped cavity of

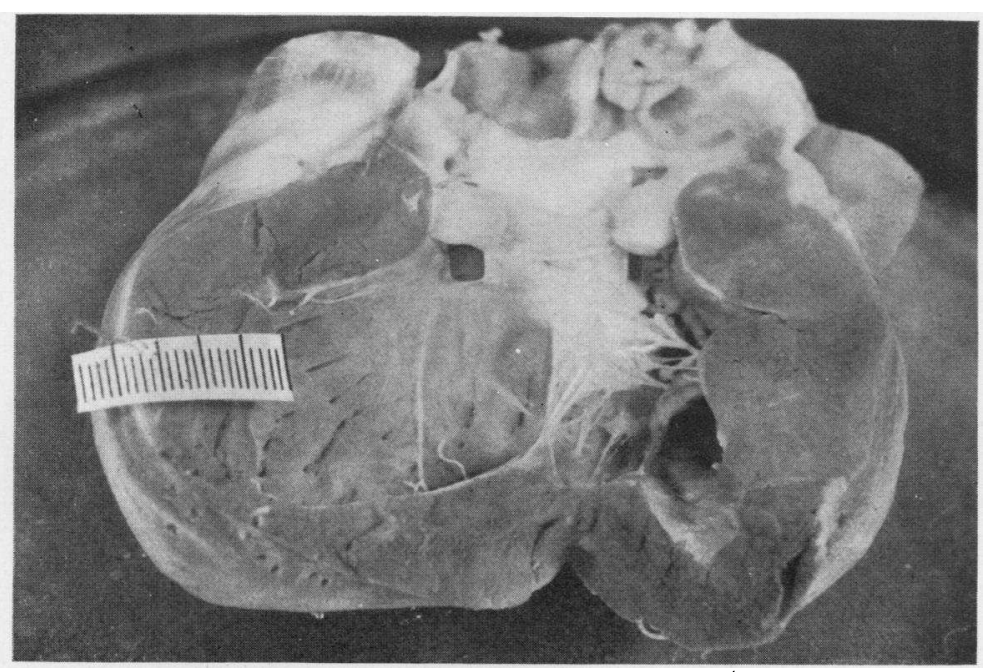

Fig. $4 a$

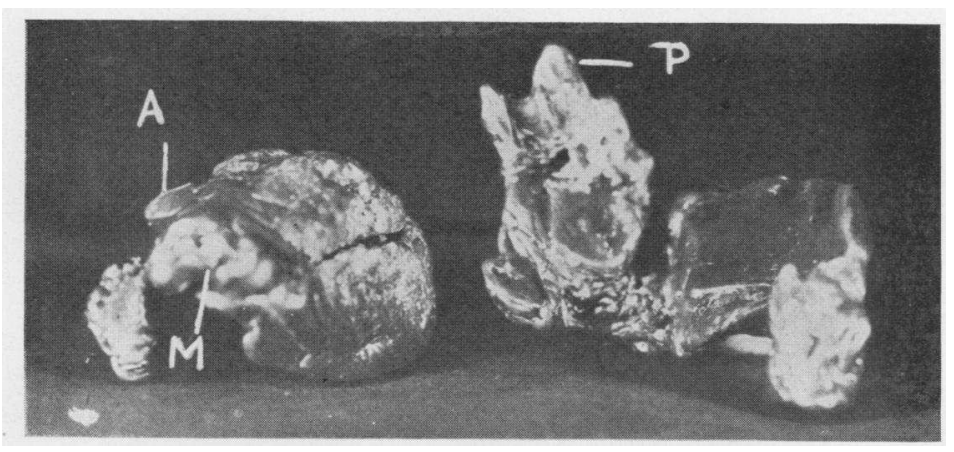

Fig. $4 b$

Fig. 4. EXPERIMENT B

a. Heart at autopsy with glass rods inserted through main holes. Millimeter scale on heart wall.

$b$. Casts of the ventricular cavities - the left conical, the right very elongated. $A$ is the aortic valve, $P$ is the pulmonary valve, $M$ is the mitral valve. 
19.5 cc. only. Figures 4 (a) and (b) demonstrate the valve lesions, and shape of the casts obtained. The ratio of ventricular weights by Lewis' method was L/R 2.8-the normal value being 2.16 (Dr. Grant).

\section{Experiment C-Dog 23}

Male, 10.5 kilos. Operated on while under the effect of atropine. Attempts were made to tear two valve cusps; at the end of the operation the pulse became quite weak and then gradually improved with an extreme water hammer type.

Figure 5 illustrates the changes in heart size demonstrating that there is definitely no dilatation, in the clinical sense, under such conditions in spite of the big lesion and the feeble pulse existing shortly before the photographs were taken. There was unquestionably an increase in the heart shadow following the operation

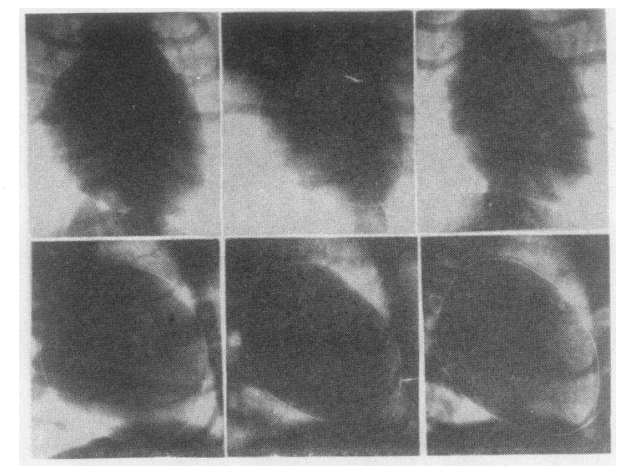

Fig. 5. EXPERIMENT C

The antero-posterior photographs were taken (from left to right) with morphine $50 \mathrm{mgm}$., with atropine sulphate in addition $11 \mathrm{mgm}$., and immediately after operation with regurgitation still under the effects of the above drugs and recovering from ether anesthesia. The pulse rates were 48, 200 and 160 respectively. The lateral photographs were similarly obtained. The areas were antero-posterior $43.3,34.8$ and 36.8 , lateral $46.1,37.4,42.1$ sq. $\mathrm{cm}$., and the lengths of the long axis $8.2,7.5,8.0$ and $8.9,8.4$ and $8.7 \mathrm{~cm}$.

particularly in the lateral photographs, but it was not outside the range that might be caused by the observed slowing of the pulse.

The electrocardiograms showed an immediate change, the $Q$ wave became exaggerated in all three leads and the $S$ wave which was originally present in Leads II and III disappeared, while the potential of $\mathrm{R}$ was exaggerated. Figure 6 shows the changes in Lead I and III; Lead II both before and after operation was very similar to Lead III. The slowing of the pulse was probably not due to the end of the atropine effect since the whole operation was completed quickly.

On the first day after the operation the animal was kept in a small cage. It 
seemed fit and took its food well. On the following day it still seemed fit, was wagging its tail and was then allowed to run about in a large room. The pulse was, however, very collapsing and irregular, the rate varying from 140 to 160 , and the respirations were fast and rather gasping. Shortly after this, its respirations became progressively faster and more laboured; it coughed up frothy fluid tinged with blood, and at midday died with lung edema.

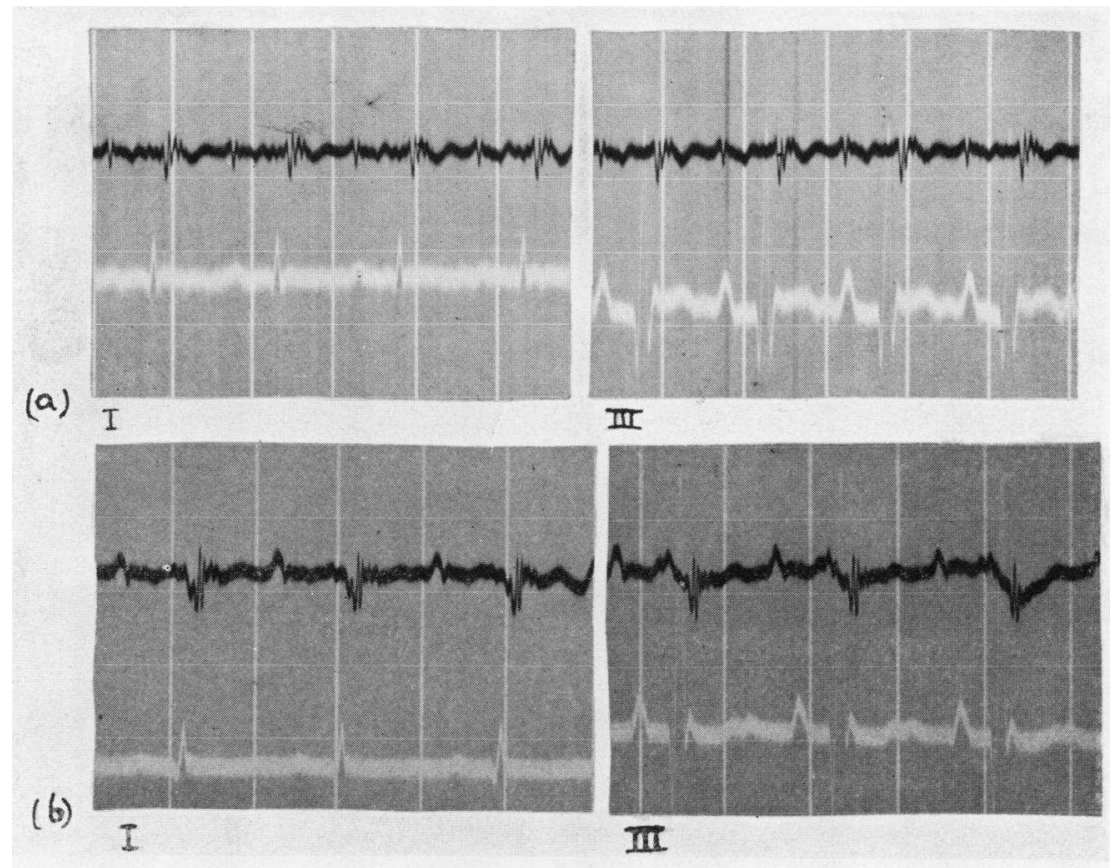

Fig. 6. EXPERIMENT C

$a$. Electrocardiogram (white) and heart sound record (black) taken immediately before operation, morphine $50 \mathrm{mgm}$., atropine sulphate $11 \mathrm{mgm}$., Leads I and III.

$b$. Electrocardiogram (white) and heart sound record (black) taken about 30 minutes later immediately after operation when recovering from ether.

Autopsy. Lungs: Edematous and congested. Liver: Congested and firm. Heart: Weight 77.5 grams $=0.74$ per cent of body weight. The right anterior cusp had been torn until a mere shred was left; the left anterior cusp had a hole $2 \mathrm{~mm}$. in diameter and the posterior cusp one $3.5 \mathrm{~mm}$. in diameter. The left ventricle was in a condition of extreme rigor mortis, the whole heart small (autopsy one hour after death) and there was no evidence at this time of gross dilatation. The amount of leak was not measured, but the aorta was perfused with water to 
cause an even water turgor and casts were then made, giving volumes for the right ventricle of $7 \mathrm{cc}$. and 6.25 for the left. $\mathrm{L} / \mathrm{R}$ ventricular weight ratio 2.1 (Dr. Grant).

\section{Experiment D-Dog 18}

Male. Originally 9.25 , finally 13.0 kilos in weight. A number of electrographic records and $\mathrm{x}$-rays taken before and after operation all under morphine

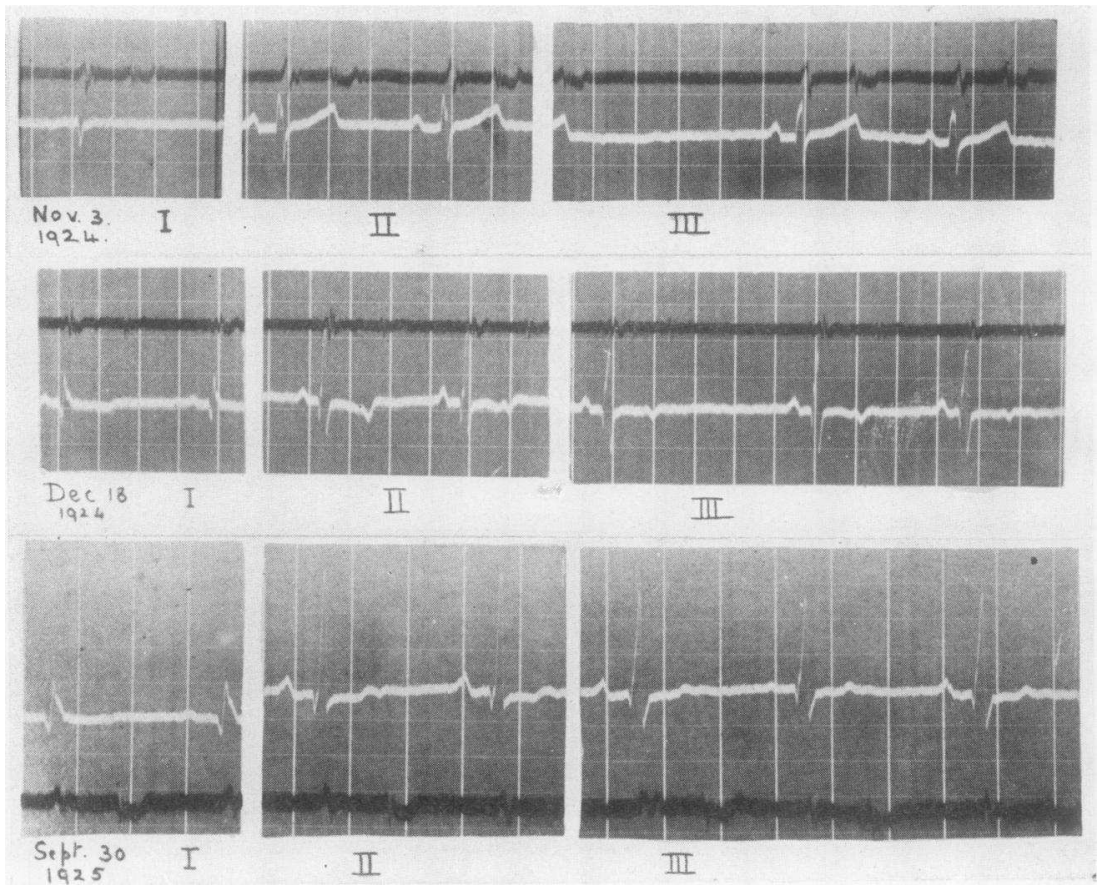

Fig. 7. Experiment D

Electrocardiograms (white) and heart sound records (black) of dog 18, all after morphine; above before any operation, in the middle 6 weeks after the initial operation and below 11 months after the initial and $9 \frac{1}{2}$ months after the second operation.

(see fig. 7 ). The animal was excitable and on the last two occasions had to have ether in addition. Records were also obtained after atropine injections.

November 7, 1924. Operated on with perforation to two valves, and immediately after operation extra systoles were noted usually of left ventricular type, but with occasional contractions apparently originating in the right ventricle. 
December 18, 1924. Reoperated with attempted stretching of old holes. Sound caught in a valve, met considerable resistance, and was eventually forced through, but doubt was felt as to actual position of the stylet which was withdrawn rapidly as the heart action became very feeble. The dog was exercised at intervals between April 3 and September 30, 1925, and during this time the amount of work it was able to do increased. For example the average work done on 5 occasions between April 27 to May 5 was 2.58 kilometers with a climb of 450 meters, while the average of 12 occasions between August 26 to September 20 was 3 kilometers with a climb of 524 meters. During warm weather in July the average work on 7 occasions was only 2.01 kilometers with a climb of 350 meters, and twice work had to be stopped, as the animal vomited while working.

The correlation of the change in the shadow of the heart with lengthening of the Q-S interval is shown in the following tabulation.

\begin{tabular}{|c|c|c|c|c|c|}
\hline \multirow{2}{*}{ Date } & \multicolumn{2}{|c|}{$\mathrm{X}$-ray area with morphine } & \multicolumn{2}{|c|}{$\begin{array}{l}X \text {-ray area with } \\
\text { morphine and atropine }\end{array}$} & \multirow{2}{*}{$\begin{array}{l}\text { Duration of } \\
\text { Q-S interval }\end{array}$} \\
\hline & A.P. & Lat. & A.P. & Lat. & \\
\hline $\left.\begin{array}{l}\text { November } 3,1924 \\
\text { November 5, 1924 } \\
\text { November } 7,1924\end{array}\right\}$ & $38.4(100)^{*}$ & $43.8(100)$ & $34.0(100)$ & $38.6(100)$ & $0.056(100)$ \\
\hline
\end{tabular}

First operation

December 18, 1924......... $48.0(125)|48.3(110)| 42.2(124)|41.6(108)| 0.067$ i120)

Second operation

\begin{tabular}{|c|c|c|}
\hline $\mathrm{Ma}$ & $49.8(130)$ & $|51.4(117)| 44.6(131)|46.4(120)| 0.074(132)$ \\
\hline Septembe & $52.2(136)$ & $51.4(117) 47.5(140) 47.1(122) 0.079(141)$ \\
\hline
\end{tabular}

* Bracketed figures indicate percentage change.

Autopsy. October 8, 1925. Blood pressure $170 / 76$ in brachial and $252 / 70$ in femoral (after ligature of other femoral) with pulse of 109. Animal killed with ether. Heart weight 105 grams ( 0.81 per cent body weight). The leak was 1.75 liters per minute. Casts gave volumes for the right ventricle of 29.3 and for the left of $34.7 \mathrm{cc}$.

The left ventricular wall was from 10 to $20 \mathrm{~mm}$. thick and the right $6 \mathrm{~mm}$. Dr. Grant reported "in the posterior cusp was an oval hole about $5 \mathrm{~mm}$. in diameter with thickened edges. The left anterior cusp was thickened at its base and on its aortic surface a small perforation the size of a pin's head was seen in the center of the thickened base. This hole led into a false aneurysm of the ventricular wall, underlying the thickening described. It was lined by a thick layer of connective tissue. The mitral valve was thickened and showed irregular flat thrombi, possibly implying a low grade inflammation though no organisms 


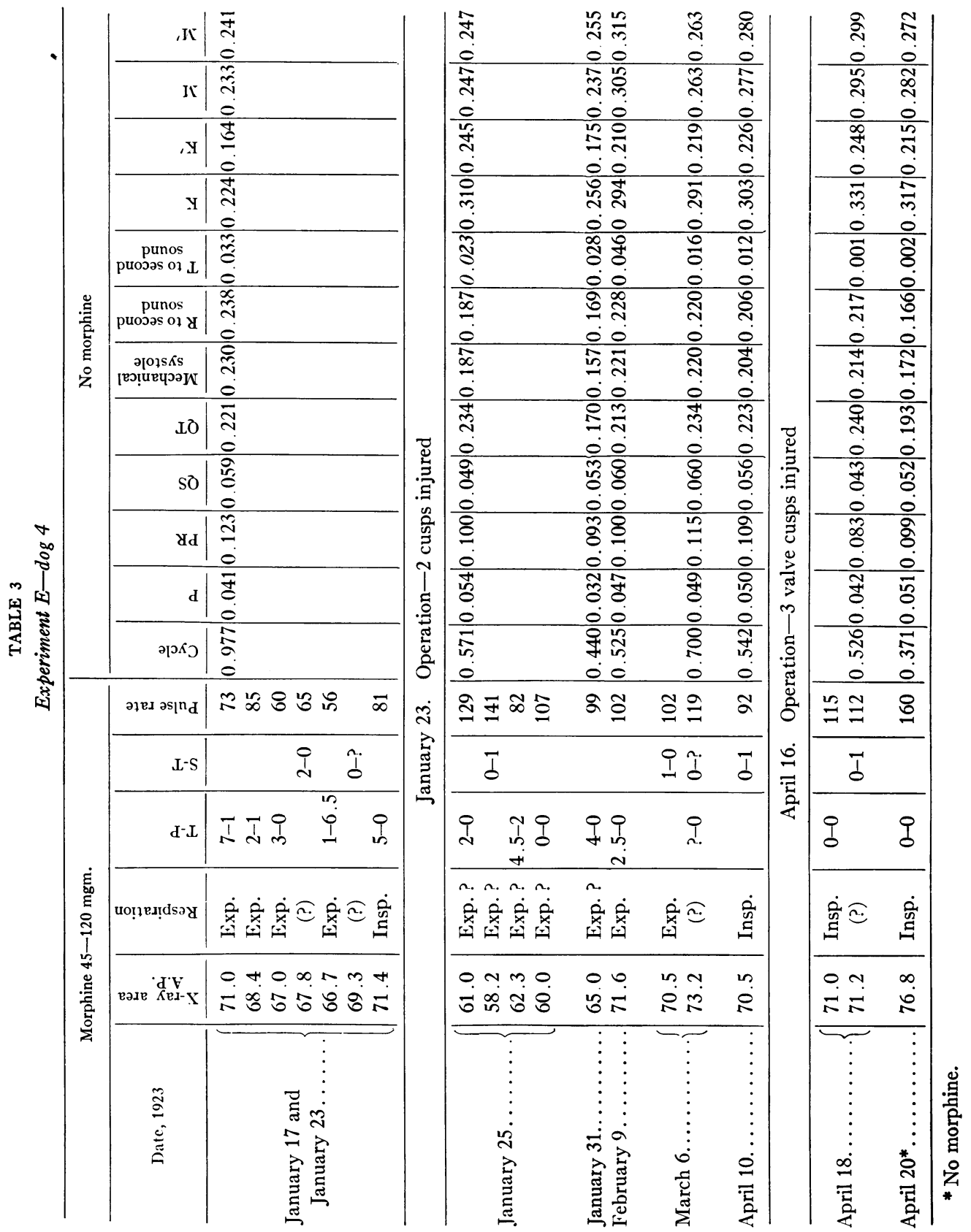


were found." The autopsy therefore makes it doubtful whether more than one valve was perforated at either operation.

\section{Experiment E-Dog 4}

Male, 14.75 kilos. Electrocardiographic records were taken with and without morphine and 47 short exposure $x$-rays were taken after morphine with a few exceptions. A few typical figures of the $x$-ray shadow areas with morphine and of the time relations of the heart cycle without morphine are given in table 3 .

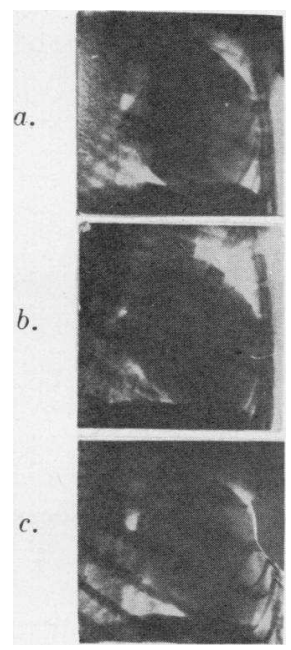

Fig. 8. EXPERIMENT E

Short exposure x-rays, (a) x-ray without morphine, 3 days before second operation. Area 68.8 sq. $\mathrm{cm}$. Long axis $11.0 \mathrm{~cm}$. Expiration S 0-T 0.5. Pulse rate 85 .

b. With morphine 2 days after operation. Area $70.0 \mathrm{sq} . \mathrm{cm}$. Long axis 11.4 $\mathrm{cm}$. Respiratory phase uncertain S 0-T 1. Pulse 114 .

c. Without morphine 4 days after second operation just before death. Area 74.2 sq. cm. Long axis $12.1 \mathrm{~cm}$. Inspiration S 0-T 0. Pulse 158.

Following the first operation there was a hematoma in the neck, from which a clear fluid drained. The second operation was unusually prolonged owing to a breakdown of the fluoroscope and the trauma great. In spite of extensive damage to three valve cusps the dog seemed quite fit on the following day, though quieter than usual. By the fourth day after operation the animal was obviously extremely ill and feverish, and died in the afternoon, about 1 hour after the last record was taken.

During the first operation the fluoroscope showed a lengthening of the shadow 
from 97 to $104 \mathrm{~mm}$. with a diminution of the transverse diameter from 92 to about $78 \mathrm{~mm}$. The breakdown of the $\mathrm{x}$-ray machine prevented such observations at the second operation, but lateral and antero-posterior photographs taken two days later (see fig. 8) demonstrated that such a lengthening had occurred.

Autopsy showed a left sided pneumonia, haemorrhagic myocarditis and a slight pericardial effusion. Weight of heart 128 grams $(0.87$ per cent of body weight). Regurgitation occurred at rate of 3.6 liters per minute.

There were four lesions in the three cusps, one cusp having two holes, and each of the others one. Two holes had fibrosed edges and a diameter of about $3 \mathrm{~mm}$.; two appeared recent and had diameters of 5 and $3 \mathrm{~mm}$. Culture of heart's blood showed the presence of haemolytic staphylococcus aureus.

The left ventricular wall seemed slightly thickened. L/R ratio of 3.8 (Dr. Grant).

\section{Experiment F-Dog 13}

Male. Initial weight 12.5 , final 17.00 kilos. No growth, but initially thin. It was allowed to take what exercise it liked on the machine on 28 occasions between December 17 and February 4, remaining on the machine for 30 minutes to 1 hour. It covered a distance averaging 3.36 kilometers with a climb of about 700 meters. Even before operation this work had some effect on the heart size. During the first three weeks of the experiment the dog had been kept in a small cage without any exercise and the areas of the heart shadows (long exposures) had decreased 4.3 per cent in the lateral and 7 per cent in the anteroposterior photographs. By January 25, after this period of exercise the shadows had increased to the original size and by February 4th they were further increased above this size (lateral 4.4 and anteroposterior 10.0 per cent).

On February 4, the animal was operated on and extensive damage caused to two cusps. On the following day extra systoles of right ventricular type were observed. Seventeen days after operation exercise was again commenced. The dog panted much more than previously, took more frequent rests, would not gallop of its own accord, though it could do so when encouraged by food. At the end of such periods it could not be made to work without great persuasion, was very short of breath, and the apex beat and pulse, which originally were bounding, became almost imperceptible. In spite of this on removal from the machine, it would run off to a good meal as usual. During this period it was exercised 4 or 5 times a week and covered on the average 2.05 kilometers with a climb of about $\mathbf{4 7 0}$ meters in 35 minutes, after which it became fatigued and was removed. Three and a half weeks after operation it resumed galloping of its own accord, but would only continue this for a short while at the commencement of its work.

Five weeks after operation the heart shadow was still slightly below the original value, and 8 to 11 per cent below the figures obtained just before operation.

At this time it was operated on again and died 5 days later of acute septic 
endocarditis. Two days after operation it resembled dog 4 (experiment E) in that it was relatively unaffected by the large lesion. Later it also showed an ante-mortem dilatation.

Six to seven hours before death electrographic records showed no extra systoles; two hours before death they were again present but of a different type to those seen after the first operation (Lead II only).

Autopsy. Weight of heart 155 grams (0.91 per cent body weight). Leak 3.5 liters per minute. One cusp had a large hole with thickened edges, another had two holes both very large and one thickened and old. Vegetations were present on both old holes and on the mitral valve, which had also been damaged. On the posterior surface of the left ventricle there was a suppurating infection almost resulting in perforation of the wall.

\section{Experiment G-Dog 14}

Male. Initial weight 16.5, final 21.5 kilos. Increase due to fat. Composite x-ray photographs with morphine and E. C. G. records without morphine. Before operation x-ray shadows averaged antero-posterior 64.7 and lateral $73.3 \mathrm{sq}$. cm. E. C. G. cycle 0.457 , QS 0.042 , and QT 0.200 second.

July 25, 1924 . Operation with puncture of two cusps.

March 3 to 30 . Exercise on 20 occasions with average distance of 3.2 kilometers and climb of 708 meters in 45 minutes. On one occasion 5.5 kilometers with climb of 1220 meters was covered in one hour.

April 11. X-ray-antero-posterior 82.5 and lateral 89.3 sq. cm. E. C. G. cycle 0.475 , QS 0.051 , QT 0.207 second. A second operation attempted and the aorta was perforated causing death.

Autopsy. Holes 3 to $4 \mathrm{~mm}$. diameter with thickened rims in both posterior cusps. The left ventricular cavity appeared large, but walls not unusually thick. Weight of heart 175 grams (0.81 per cent of body weight). L / R ratio 2.7 (Dr. Grant).

\section{Experiment $H-D o g 16$}

Male. Initial weight 14.5, final 13.5 kilos; and became very thin through vomiting. Records as in experiment G. Animal very athletic, and able to jump out of all usual cages. Initially $\mathrm{x}$-ray shadows-antero-posterior 60.6, lateral 67.7 sq. cm $\quad$ E. C. G. cycle 0.938 , QS 0.050, QT 0.268 .

March 6, 1924. Section of right vagus in chest just below recurrent laryngeal. (We are indebted to Dr. Sweet for the performance of this operation.)

March 22. X-ray-antero-posterior 56.6, lateral 64.3 sq. cm. E. C. G. cycle 0.560 , QS 0.044 , QT 0.234 . Section of left vagus.

April 2. Vomiting frequently during last week. X-ray-antero-posterior 59.6, lateral 58.6, pulse 88, at this time (under morphine). E. C. G. cycle 0.499, QS 0.054, QT 0.243. Operation-damage to 2 cusps. X-ray-antero-posterior 53.0, lateral 60.3 sq. cm. Pulse rate at this time (with morphine) 112. 
April 3. X-ray-antero-posterior 53.1, lateral 54.6 sq. cm. E. C. G. cycle 0.488, QS 0.051, QT 0.228.

April 5. E. C. G. cycle 0.501, QS 0.045, QT 0.224.

April 6. Died apparently from weakness secondary to vomiting.

Autopsy. Right vagal stumps included in scar tissue, and one branch to heart coming off above section. Lungs edematous and congested. Liver "nutmeg" in appearance. Regurgitation at 2.2 liters per minute with 1 meter pressure of saline. Large holes in two cusps. Heart weight 132 grams (0.91 per cent of initial body weight). L/R ratio (Dr. Grant) 2.3 .

\section{Experiment I-Dog 19}

Male. Initial weight 14, final 18.6 kilos. (Initially very underweight.) $\mathrm{X}$-rays and E. C. G. records all after morphine.

January 22. Before operation-x-ray shadows-antero-posterior area 62.6 sq. $\mathrm{cm}$. Length $9.6 \mathrm{~cm}$. Lateral 68.9 and length 10.9. (Pulse rate 60.) After atropine sulphate $20 \mathrm{mgm}$. Antero-posterior 57.1. Length 9.9. Lateral 57.2 sq. cm. Length $10.5 \mathrm{~cm}$. (Pulse rate 225.) E. C. G. (one occasion only after morphine) cycle 0.978 , QS 0.071 , QT 0.302. Operation-damage to two cusps.

January 24. X-ray shadows-antero-posterior 58.4 sq. $\mathrm{cm}$. length $9.8 \mathrm{~cm}$. Lateral 64.3. length 10.8. (Pulse rate 115.) After atropine sulphate-anteroposterior 52.5, length 9.2. Lateral 53.1, length 9.9. (Pulse rate 220.) E. C. G. Cycle 0.714, QS 0.055, QT 0.278.

February 20. Developed partial paralysis of both hind limbs following a fight.

February 25. Paralysis not improved. X-ray shadows-antero-posterior 69.0 sq. cm., length $9.9 \mathrm{~cm}$. Lateral 73.3, length 11.3. (Pulse rate 126.) After atropine sulphate antero-posterior 67.0, length 10.6. Lateral $65.0 \mathrm{sq} . \mathrm{cm}$. length $11.0 \mathrm{~cm}$. (Pulse 205.) E. C. G. cycle 0.767, QS 0.056, QT 0.286. Killed with chloroform.

Autopsy. Heart: Holes about $3 \mathrm{~mm}$. in diameter present in both posterior cusps. Left ventricular cavity $41.3 \mathrm{cc}$. right $26.2 \mathrm{cc}$. Weight of heart 144 grams ( 0.77 per cent of final body weight).

Spinal cord: Evidence of embolism in lowest sacral segments. Macroscopic examination did not demonstrate a higher lesion such as was indicated by the symptoms before death.

\section{RESULTS}

\section{Signs and symptoms}

An immediate increase in pulse rate was the invariable accompaniment of the production of a lesion in our animals, except when the pulse rate was already high as the result of an atropine injection, when on the contrary there was a slight, but quite definite slowing. The 
following day and during the next few months the pulse rate gradually slowed, but never returned to its previous low level, whether observations were made with or without morphine. The slowing of the pulse by morphine was much less noticeable after the operation. In every case the pulse was of a water hammer type of varying degree but often extreme.

There was no obvious disability, nor even, as will be seen later, any great loss of power to do work as the result of a single operation with damage to one or two valve cusps. With damage to three valves, if performed in two stages, a stranger would have considered the dog absolutely normal even on the first day after operation, though we could recognize that the dog's expression of pleasure at our entering the room was less violent. In strong contrast was the immediate death of dogs, which occurred if lesions of this extent were made at a single operation.

The protocol of experiment $B$ gives an example of an enormous change in pulse rate at such a second operation without any other obvious symptoms, and the photograph reproduced indicates the magnitude of the lesion. Immediately after the second operation before the partial healing of the one cusp, the lesion must have been even more severe.

The general signs of aortic regurgitation such as diastolic murmurs (always audible and sometimes recordable photographically), precordial thrill, capillary pulsation, and the so-called differential blood pressure were commonly present.

The differential pressure was measured in two animals which had had an aortic lesion for nearly 1 year; the difference amounted to only $16 \mathrm{~mm}$. in one case (experiment B) and to $82 \mathrm{~mm}$. in the second (experiment D), but in the latter the other femoral had been tied, so that the difference was somewhat exaggerated (21). There was, therefore, no evidence of any marked contrast between the acute and chronic animals (21). No macroscopic evidence of arteriosclerosis could be detected. No capillary pulsation could be detected in the mouth during the first 24 hours, but it was usually present on the second day; the slow development agreed with Lewis's (23) conception of a slow development of vasodilatation. In our experiments, however, no such definite deduction would be warranted after liga- 
ture of one or both carotids. Decompensation of gradual onset was only seen in one animal (experiment C). .

\section{Electrocardiographic changes}

There was no regularity in regard to immediate changes in the electrocardiograms. In some animals there was at once an exaggeration of the $Q$ wave and diminution of the $S$ in all leads (experiment $\mathrm{C}$ ), but often no such immediate change in $\mathrm{Q}$ or $\mathrm{S}$ was recognizable. Usually the $P$ wave was exaggerated and the extreme potential differences reached in the QRS group increased, but this was not constant and there was considerable variation in the alteration of any one wave.

On the other hand in the records obtained after the survival of the animal for some time the changes were very consistent The potential of the $\mathbf{P}$ wave was nearly always increased, particularly in Lead II and III and its duration was greater. The $Q$ wave had a much increased potential in all three leads. The potential of the $R$ wave was less constantly changed; but again was commonly increased in all leads. The S wave became diminished in Leads II and III; no $\mathrm{S}$ wave was noticed in Lead I, either before or after operation. The changes in the $T$ wave were irregular; the potential might be increased, decreased, or the wave might be inverted; very commonly it was a double wave, both before and after operation. The changes in the character of waves in such chronic animals are illustrated in figure 7 representing the changes seen in experiment $D$. The ultimate changes seen in the electrocardiograms, except in the duration of the waves, were very similar to those which sometimes occurred immediately after operation. Both would be explicable as the result of a rotation of the heart (28). It should be pointed out that the bizarre curves seen in figure 7 (notching of the $R$ and duplication or inversion of the $\mathrm{T}$ wave) probably have no special significance; such variations are not at all uncommon in apparently normal dogs. There has never been any evidence of one-sided preponderance of the type described clinically. The parallelism between the changes in heart size and the average duration of the Q-S group typical of that occurring in the whole series is noticeable in the records of experiments $D$ and G. A similar parallelism is seen in table 2 and to a 
less extent in table 1 (contrast experiment $\mathrm{I}$ ); it is the more surprising since any individual measurement of the Q-S group may have a serious error, since the electrical changes in the two ventricles may neutralize and mask one another.

Extra systoles of ventricular origin were seen immediately after operation or within the next few days in 8 out of the 11 survivals, and in every animal that was examined at all frequently after operation. In nearly every case they were of left ventricular origin and occurred in groups of 4,5 or more; in one animal (experiment D) premature left ventricular contractions occasionally alternated with others of right ventricular type immediately after the first operation, but the autopsy findings are difficult to interpret. In experiment $\mathrm{F}$ extra systoles of right ventricular type occurred on the day following the intial operation. In the same dog several days after the second operation and just before death from infection extra systoles were again seen and though only recorded in Lead II, they were of quite a different type from those seen earlier.

\section{Time relations of the cardiac cycle}

In general the changes observed in the duration of systole and diastole were the same in both electrical and mechanical records; whatever differences between the two occurred were mainly seen in the first few days following operation. Following aortic regurgitation systole was relatively long for the pulse rate existing at the time. This may be readily seen in the figures given for experiments A, B and $E$ by the changes in the factors $K$ and $M$ already described (19), which represent the relation of systole to the square root of the cycle. In the earlier weeks after operation the lengthening is partly in the S-T interval and causes an increase in the value $\mathrm{K}^{\prime}$ as well as in $\mathrm{K}$; later with the development of hypertrophy the Q-S interval is increased (see experiment $\mathrm{D}$ ), and the $\mathrm{S}-\mathrm{T}$ interval sometimes returns to a normal length, $\mathrm{K}$ being still increased, but $\mathrm{K}^{\prime}$ increased or normal (experiments A, B and E). The changes of the mechanical systole follow the same course as those of the electrical, except immediately after operation when the relationship of the $T$ wave to the second sound is very variable, and consequently the two figures do not necessarily go always in the same direction. The discrepancy 
between the two which may occur even under normal conditions after morphia is well demonstrated in figure 7 . The values given in table 3 without morphine suggest that some factor may make the $T$ wave outlast the second sound particularly just after the production of an aortic lesion. Of six animals where a series of records were taken without morphine four showed a $\mathrm{T}$ outlasting the second sound to an unusual extent during the first few days after operation. It did not appear to be dependent on excitement.

There was also seen at times an apparent discrepancy between the first sound and the QRS group; after operation a large abrupt vibration was sometimes seen which would have been considered the beginning of the ventricular first sound, if it had not occurred considerably before the $Q$ wave. Such sounds were presumably auricular in origin and were disregarded in estimating mechanical systole.

Diastolic murmurs though audible were only occasionally recorded clearly; sometimes they were most evident in early diastole, sometimes in late diastole, almost merging with the first sound. The records reproduced in figure 3 from experiment $\mathrm{B}$ show in $(a)$ a small early diastolic murmur due to the lesion produced at the first operation 7 weeks earlier; in $(b)$ obtained immediately after the second operation there is a very definite murmur extending throughout diastole up to the first sound. The pulse rate had risen as the result of the operation from 122 to about 200 and in record $(b)$ the $T$ and $P$ waves are partly fused.

\section{Changes in heart size}

In another paper (19) the variations in heart size seen in these dogs under normal conditions have been discussed, and it will be seen that changes in size beyond the experimental error are demonstrable by $\mathrm{x}$-ray after operation.

Immediate changes. The fluoroscope demonstrated at the time of operation an immediate change in the shape of the heart. Almost invariably measurements on the screen showed a lengthening of the heart shadow usually accompanied by a diminution of the transverse diameter. On the other hand in one case, which involved damage to three cusps within a few minutes, a marked increase in both diameters was observed, the length increasing from 89 to $102 \mathrm{~mm}$. and the 
breadth from 74 to $79 \mathrm{~mm}$. The animal, however, died about five minutes later with a terminal ventricular fibrillation. At autopsy one cusp was partially detached, and may have possibly obstructed the right coronary orifice. In one other animal, with only an average amount of damage to two cusps, dilatation was demonstrable immediately after operation, the heart area being increased above the normal value by 2 per cent in the anterio-posterior photograph and by 17 per cent in the lateral. The animal was dying and at the time of examination no pulse could be felt; though it was still breathing. This was the minimal valve lesion which caused immediate death. In surviving animals there was no visible dilatation and occasionally none might be demonstrable even shortly before death. For instance in one other animal which died on the table from a lesion to three valves at a single operation, the shadow only lengthened on the fluoroscope from 84 to $91 \mathrm{~cm}$., while its transverse diameter was reduced from 81 to 60 . This absence of dilatation in the clinical sense has been most striking. Experiment $\mathrm{E}$ illustrates the degree of change usually observed with the fluoroscope in animals which survived.

Early changes. Immediately after operation, the following day, and generally at any time during the first week, the heart shadow in diastole was smaller than any systolic area before operation. This is clearly seen in the records of experiments A and E. Occasionally the photographs taken within a half hour of the operation showed the lengthening already described; more often it was slight and certainly less marked than that seen by fluoroscope during the operation. In experiment $\mathrm{E}$ there was seen a decrease in the diastolic heart shadow two days after the first operation (table 3 ), which amounted to about 13 per cent and even after a week was still 7 per cent. If the diminution were due to the pulse rate change alone, and the curve followed was similar to those of Meek's animals (24), only a diminution of 5 to 8 per cent on the first occasion and of 2 per cent on the second might have been expected. With this diminution in size there occurred an initial lengthening of the heart demonstrable on the fluoroscope, though $\mathrm{x}$-ray photographs taken on the following day did not show it. After the second operation, when the leak was enormous, the antero-posterior shadow was slightly increased even 
though the pulse rate was faster, the lateral photographs (see fig. 8) showed a more definite increase, and the lengthening was now obvious.

Late changes. After a short while, a progressive but slowly developing heart hypertrophy became evident. This may be observed in the values already given for experiments $\mathrm{A}, \mathrm{B}, \mathrm{D}$ and $\mathrm{E}$ and the hypertrophy is confirmed by the weight of the heart at death, as well as in experiments $B$ and $E$ by the ratio of the weights of the two ventricles. On the other hand, it is noticeable that such a hypertrophy may be masked in $\mathrm{x}$-ray shadows by the effect of the pulse rate change. In experiment $E$ there was in our opinion a hypertrophy, though the actual areas of the heart shadow merely showed a gradual recovery of the original size (if the last day before death be excluded). The later areas, however, were obtained with a pulse rate of about 115 and were approximately as large as those obtained with a pulse rate of about 70 before operation; with the change in the pulse rate a smaller heart shadow might be expected and its absence demonstrated the hypertrophy.

The effect of such pulse rate changes can be avoided by the comparison of shadows obtained when the animal is under the effect of atropine. Data so obtained have been given for experiment $D$. Experiment B showed the greatest change in the heart shadow that we have observed, and yet even after atropine injection the shadow area remained much above the value originally found with a slow pulse; unfortunately atropine was not used in this case previous to operation.

Ante-mortem dilataiion. A dilatation, demonstrable by $\mathrm{x}$-rays, is present in dogs with an acute infection just before death (experiments $\mathrm{E}$ and $\mathrm{F}$ ) but the great lengthening of the heart seen in experiment $\mathrm{E}$ was not a constant finding.

\section{Ability to do work}

Some of the animals were tested on the treadmill already described. In order to be able to make a rough comparison of the capacity of the aortic animals with that of a normal animal, a single dog (experiment F) was allowed to do work both before and after operation. This experiment suggests that the amount of work that an animal 
can do may be reduced, even though a superficial examination does not demonstrate any disability. On the other hand, the amount of work done after operation was surprisingly great, considering the extent of the lesion and the probability of the existence in this animal of a subacute infection dating possibly from the original operation.

The absence of any obvious disability was also well demonstrated by $\operatorname{dog} 14$ (experiment $\mathrm{G}$ ), which did more work after operation than did $\operatorname{dog} 13$ before operation.

The protocol of experiment $B$, that has been given already demonstrates that with a considerable leak as the result of two operations the ability to do work may be much more reduced, and under these conditions a high room temperature had a much more depressing effect, and signs of discomfort and vomiting were then often seen. The data of experiment D demonstrate a similar effect, though to a less degree, and in this case the symptoms disappeared during the last month of life. The vomiting, occurring during the work or soon after in experiments $B$ and $D$, appeared to be associated always with over fatigue and dyspnea.

\section{Gross pathology}

Examples have already been given which illustrate the type of change observed at autopsy. There seems to be no doubt that after a few weeks or months the weight of the heart is somewhat increased so that heart weight to body weight ratios greater than those considered normal by other workers have generally been observed. This ratio is so variable in dogs, that the figures obtained in any particular dog are rarely outside normal limits, but the consistent high ratios are significant.

The figures given by Joseph (29) show quite definitely the variation of the ratio in supposedly normal dogs with varying weight and demonstrate that the normal ratio for male dogs of the smallest size that we have used (9-10 kilo) would be about 0.72 per cent, while for the larger animals (e.g., dog 14) it would be less and probably about 0.64 per cent; comparison should, therefore, be made after considering the absolute weight of the dog.

Table 4 will demonstrate the difficulty of judging by mere weight ratios.

THE JOURNAL OF CINIICAL INVBgTIGATION, VOL. III, NO. 1 
The average weight of the first group was 12.31 kilo and the average ratio 0.796 , the corresponding values for the second group was 15.15 kilo and 0.86 . If, however, comparison is made with only the first 5 dogs of the second group, in order to have comparable body weights (average weight of the 5 dogs 12.64 kilos), the ratio observed after

TABLE:

\begin{tabular}{|c|c|c|c|c|c|c|c|c|}
\hline \multirow{2}{*}{ Number } & \multirow{2}{*}{ 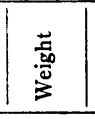 } & \multirow{2}{*}{ 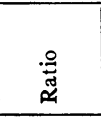 } & \multirow{2}{*}{ 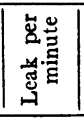 } & \multirow{2}{*}{ Survival } & \multirow{2}{*}{ 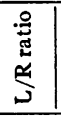 } & \multicolumn{2}{|c|}{ Casts } & \multirow{2}{*}{ Remarks } \\
\hline & & & & & & $H$ & $\propto$ & \\
\hline \multicolumn{9}{|c|}{ Acute death or short survival } \\
\hline & & & liters & & & & & \\
\hline 20 & 9.25 & 0.81 & & & & 9.7 & 27.5 & $\begin{array}{c}\text { Probably rigor at } \\
\text { autopsy }\end{array}$ \\
\hline 23 & 10.5 & 0.74 & & 3 days & 2.1 & 0.25 & 7.0 & Rigor at autopsy \\
\hline 21 & 13.0 & 0.82 & & & & $|23.7|$ & 22.8 & (See fig. 9) \\
\hline 22 & 14.3 & 0.70 & & 4 days & & 21.0 & 26.7 & \\
\hline 16 & 14.5 & 0.91 & 2.2 & 4 days & 2.3 & & & Athletic \\
\hline Average. . & $|12.31|$ & 0.796 & & 2 days & 2.2 & & & \\
\hline \multicolumn{9}{|c|}{ Longer survival } \\
\hline 3 & 10.0 & 0.91 & 2.3 & 6 weeks & & & & \\
\hline 15 & 12.25 & $1.15(?)$ & 2.8 & 10 months & 2.8 & 27.0 & 19.5 & Exercise (see fig. 4) \\
\hline 18 & 13.0 & 0.81 & 1.75 & 11 months & & 34.7 & 29.3 & Exercise \\
\hline 17 & 13.25 & 0.88 & & 6 weeks & 2.8 & 29.0 & 20.0 & $\begin{array}{l}\text { Large holes in two } \\
\text { cusps }\end{array}$ \\
\hline 4 & 14.7 & 0.87 & 3.6 & 3 months & 3.8 & & & \\
\hline 7 & 17.0 & 0.65 & 2.7 & $4 \frac{1}{2}$ months & 2.9 & & & \\
\hline 13 & 17.0 & 0.91 & 3.5 & 5 weeks & 3.0 & & & \\
\hline 19 & 186 & 0.77 & & 1 month & 2.9 & 41.3 & 326.2 & $\begin{array}{l}\text { Exercise. Large holes } \\
\text { in two cusps }\end{array}$ \\
\hline 14 & 21.5 & 0.81 & & 11 weeks & 2.7 & & & $\begin{array}{l}\text { Exercise. Large holes } \\
\text { in two cusps }\end{array}$ \\
\hline Average. & 15.15 & 0.86 & & 4 months & 3.0 & & & \\
\hline
\end{tabular}

the existence of a lesion for an average of $5 \frac{1}{2}$ months is 0.92 , demonstrating the considerable change which results from operation. The danger of drawing too definite conclusions from individual ratios is well illustrated by $\operatorname{dog} 7$, which showed a heart weight ratio little, if at all, above the normal average, yet the heart shadow (anteropos- 
terior) increased 6 to 7 per cent above the area observed before operation in spite of the pulse rate rising from 61 to 103 .

The ratio of the weight of the left ventricle as compared with the right was determined according to Lewis's method by Dr. Grant in some of the dogs (see table 4). The ratio found by him in 5 normal dogs averaged 2.16 with extremes of 1.9 and 2.3. Of the two animals with aortic lesions showing a ratio within the normal limits $\operatorname{dog} 16$ (experiment $\mathrm{H}$ ) survived the aortic lesion for only 4 days, dying from continued vomiting secondary to vagal section. This dog was obviously athletic, and in agreement with this history

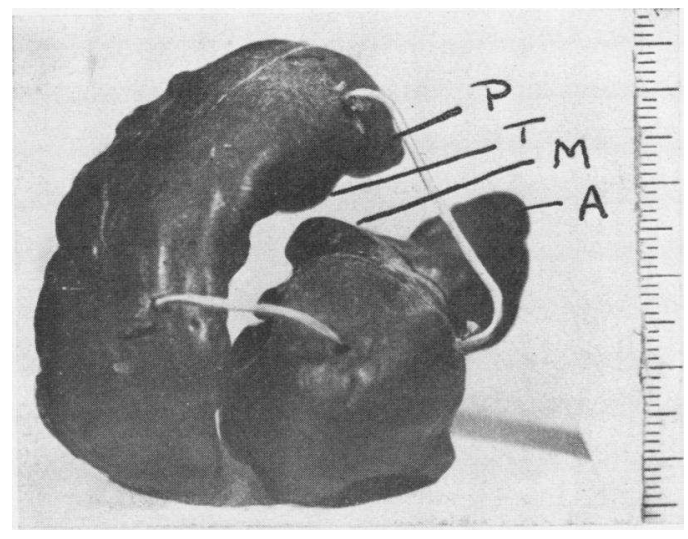

Frg. 9. Casts of ventricle in dog 21 (table 4) which died on operating table giving normal relationship of ventricles. Letters as in $4(b) ; T$ is tricuspid valve.

the heart at autopsy was large, but the hypertrophy was symmetrical. All the other animals showed a definite increase in the relative weight of the left ventricle, even dog 7 which showed the low heart to body weight ratio. Some correlation between the degree of leak and the abnormality of the left to right ventricular ratio can be seen in the table.

This increase in the weight of the left ventricle may perhaps be correlated with an increase in its cavity as compared with that of the right. This increase was obvious at autopsy, and was measured by casts in a few cases (see table 4 and compare figure $4 \mathrm{~b}$ from dog 15 with figure 9 from $\operatorname{dog} 21$ ). Agreement between the values for the 
cavities of the two ventricles was only seen in operated animals if they died immediately or shortly after operation. The casts obtained a few days after the production of the lesion show that if there is an immediate dilatation of the left ventricle following the lesion, it is not demonstrable at autopsy.

The occurrence of infection has been already mentioned (experiments $\mathrm{E}$ and $\mathrm{F}$ ) with the appearance in experiment $\mathrm{F}$ of a localized necrotic area in the left ventricular wall, which may have originated as an infarct. It was noticeable that a few hours before death numerous extra systoles were observed. Extra systoles of left ventricular type were common soon after operation, when damage to the left ventricular septal wall probably occurred and evidence of which could sometimes be found at autopsy; occasionally extra systoles of the right ventricular type were seen.

The only other complication observed was the appearance of partial spinal paralysis of both legs in experiment I.

\section{GENERAL DISCUSSION}

One of the most definite changes was an immediate increase in pulse rate, the heart action slowing again somewhat as the heart hypertrophied, but never again regaining its previous low level. This change in rate has either not been observed, or where observed, in our opinion, has not been given sufficient attention in the work of previous writers. In acute experiments the figures given by $\mathrm{H}$. A. Stewart (6) and the tracing reproduced by Wiggers (10) show little change in pulse rate and sometimes an actual slowing; this perhaps corresponds with the slowing of the pulse in our experiments, when the initial pulse was fast from atropine injections. It is conceivable that in any damaged heart, an impairment of the coronary circulation might occur sufficient to interfere with the heart's action. Hasenfeldt and Romberg noted a moderate increase in pulse rate following the operation but did not lay any stress on it. The tracings reproduced by Marey from experiments on the horse show an enormous increase in pulse rate entirely comparable to ours. The immediate occurrence of the change suggested some reflex effect on the heart. The factors causing variation in pulse rate have recently been investigated by Anrep and Segall (30). It seems unlikely that changes 
in the cerebral pressure occur sufficient to produce the result observed, but if the reflex is of the Bainbridge type it can hardly be due to distension of the right side of the heart.

The initial diminution in heart size must be partly dependent on the change in heart rate. Figures have already been given, however, which suggest that the change is greater than that to be anticipated from this cause (experiment $\mathrm{E}$ ). The values obtained in experiment $\mathrm{H}$ after vagal section give a similar impression. The figures afford some indication of an actual increase in "tone" of the heart muscle and suggest that some change has taken place enabling the heart to do its work efficiently with a smaller initial volume. Therefore the contention of $\mathrm{H}$. A. Stewart that the tone may be increased is sup-

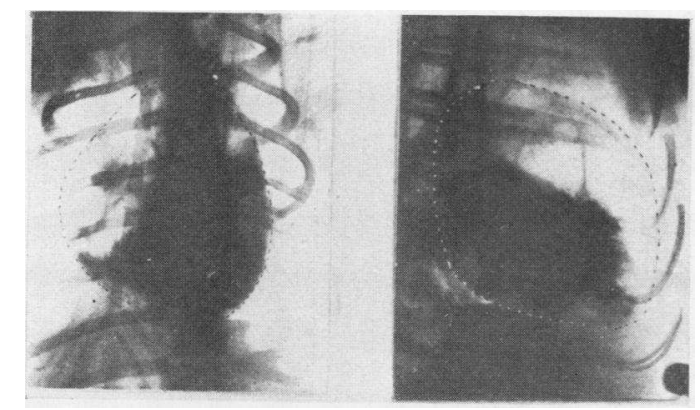

FIG. 10. Shadows of left ventricle obtained in normal dog immediately after death.

ported but certainly is not proved, since no determinations were made of the pressures distending the heart in diastole.

The x-ray shadows measured are produced by all the chambers of the heart and the left ventricle only contributes a small proportion. By injecting after death a strong solution of sodium iodide into a normal dog, x-ray photographs were obtained of the left ventricle after death which are reproduced in figure 10; the left ventricle was responsible for only 44 per cent of the shadow in the antero-posterior plane and for 60 per cent in the lateral. Diminution of the total shadow does not, therefore, necessarily exclude dilatation of the left ventricle.

If one considers a condition in which the pulse rate is changed by 
about 100 per cent as the immediate result of the operation (as in experiment $\mathrm{E}$ ) and if one supposes little change in the total circulation rate, then the right ventricle must expel only 50 per cent of the previous volume per beat, and a similar diminution must occur in the filling of the auricles. But the left ventricle is to some extent filled also from the aorta and may conceivably be distended to its normal value or even beyond this, in spite of the faster pulse, if the pendulum blood is of any appreciable amount. Against this possibility are the repeated observations of a diminution in heart size exceeding Meek's values; in favour of it is the common occurrence of an actual lengthening of the heart shadow observable on the fluoroscope, and sometimes, but not always, in photographs taken on the following day. Such a lengthening could be readily accounted for by an uneven filling of the two ventricles, so that the left ventricle was completely filled, while the right formed a lengthened narrow cavity lying along the cone-shaped left ventricle (compare experiment B). Such an hypothesis would also explain a tendency to a smaller decrease in the size of the lateral shadow than in the anterio-posterior following operation, since the left ventricle would under such conditions be responsible for a larger share of the lateral shadow.

The question as to whether a real leak of a considerable quantity of blood back into the ventricle is possible must be considered. Stewart has rejected this hypothesis on heart plethysmograph values, but these have the same fallacies as have our x-rays. Wiggers has assumed the possibility of the occurrence of a regurgitation of pressure with only minimal exchange of fluid, a hypothesis which is difficult to comprehend, if the heart muscle retains its normal elasticity. A regurgitation of fluid lasting throughout diastole is indicated by the murmurs, which characteristically last the greater part of diastole and which in experiment $B$ were recordable throughout this period. Actual measurements of the leak in our animals at autopsy demonstrate that with a pressure difference of $73 \mathrm{~mm}$. of $\mathrm{Hg}$ regurgitation would have occurred at the rates which might reach as high as 3.6 liters per minute. An approximate estimation of the actual leak during any diastole can, therefore, be made. For instance, in experiment B there was on December 12, 1924, a pulse rate of 99 and a diastole, measured from heart sound records, of 0.390 seconds. 
At autopsy the leak was found to be $46.7 \mathrm{cc}$. per second with a pressure of 1 meter of saline $(73 \mathrm{~mm}$. of $\mathrm{Hg}$.). If the isometric relaxation phase (11) lasted 0.022 second, there would remain 0.368 second during which regurgitation might conceivably occur. At the time of death the diastolic pressure was found to be about $50 \mathrm{~mm}$. If the mean pressure difference between the aorta and left ventricle during the above period was $73 \mathrm{~mm}$. the leak should have been $17.2 \mathrm{cc}$; if, however, this pressure difference was less and possibly about 30 $\mathrm{mm}$. (supposing mean pressure during diastole about 55 and the intraventricular pressure as $25 \mathrm{~mm}$.) the leak ought to be about $7.0 \mathrm{cc}$. Such a value for the regurgitation would be similar to the difference in volume of the two ventricles observed at autopsy. 'Taking Marshall's figures (31) for the normal output of a heart per minute in dogs and dividing by the pulse rate in this dog at the time, one can anticipate that the normal output of the left ventricle per beat would be about $15.8 \mathrm{cc}$. Then any such leak would mean a pendulum blood nearly 50 per cent of the normal output of the ventricle and certainly not negligible.

If the values for dog 18 (experiment $\mathrm{D}$ ) with a pulse rate of 97 be treated in a similar way, a leak of $11.3 \mathrm{cc}$. would be probable with a difference in pressure of $73 \mathrm{~mm}$. of $\mathrm{Hg}$. The actual diastolic pressure just previous to death was about 70 . The difference in the capacities of the two ventricles was $5.4 \mathrm{cc}$. as measured by casts at autopsy, and a leak of this amount would be expected if the mean difference between the aortic and ventricular pressures during diastole was about $35 \mathrm{~mm}$. $\mathrm{Hg}$. It is somewhat remarkable, and perhaps a mere coincidence, that the leaks calculated from the duration of diastole for a pressure difference of 30 to $35 \mathrm{~mm}$. $\mathrm{Hg}$ are in both animals almost the same as the differences in the ventricular cavities.

A complete set of data is not available for any other animal, since the rate of leak was often not measured, in case that procedure might distort the casts. In experiment I ( $\operatorname{dog} 19)$ the lesion was of such a size that a leak of slightly above the average, say 3 liters per minute, might be assumed. The differences between the ventricular casts exceeded that of any other animal amounting to $15.1 \mathrm{cc}$. The heart shadow was also much lengthened. This seems to be correlated with an unusually slow pulse (81) for an aortic regurgitation and with a 
long diastole of 0.5 second, which would give a leak of $23.9 \mathrm{cc}$. for a pressure difference or $73 \mathrm{~mm}$. or one of $15.1 \mathrm{cc}$. if the pressure difference were $46 \mathrm{~mm}$., which is not an impossible figure. There appears, therefore, to be some definite relationship between the amount of the leak, the duration of diastole, and the discrepancy between the two ventricular cavities.

Taking this variation in ventricular capacity into consideration it seems probable that the course of events after the production of a lesion is that at first the left ventricle is distended with much more blood than the right, giving a relative dilatation of the left ventricle, and the $x$-ray photographs in certain cases with a large leak give evidence in the lengthening of the heart that the actual size of the left ventricle may be above that existing normally; more commonly the left ventricle, if dilated, is not large enough to produce such a measurable lengthening. Any such increase in size of the left ventricle during the early stages must depend on a maintained increase in the internal pressure such as that described by Wiggers (11), since three to four days after the production of a lesion (see dogs 22 and 23, table 4) the left ventricular cavity at autopsy was certainly not larger than the right.

Later hypertrophy develops, as indicated by the increased weight of the heart at autopsy, by an increased $L / R$ ventricular weight ratio, and by $\mathrm{x}$-rays which demonstrate an increase in the total area of the heart shadow (but sometimes only after making allowance for the opposite change resulting from the increased heart rate). The development of such a hypertrophy is apparently in progress within 3 to 7 days, since by this time the heart shadow is increasing (see experiments $A$ and $E$ ). The figures of experiment $B$ where the increase in heart size was the largest we have observed, show the greater part of this increase had occurred within four months after the initial operation and within two months after the second, and that after this time only a very gradual change was seen in spite of the animal receiving exercise. The measurement of the degree of hypertrophy is complicated by the slowing of the pulse which seems to parallel the development of hypertrophy. The evidence provided by the $L / R$ ratios, by the casts, and by ventricular walls which appear of at least a normal thickness, suggests that the hypertrophy leads to an increase in the length of the fibers around a larger cavity as well 
as to changes in fiber thickness. A heart seen at autopsy having a thick wall associated with an enlarged cavity should, therefore, be classed as hypertrophied rather than dilated, and may be found in a dog whose activity precludes any possibility of decompensation being present (experiment D). This sequence of events is that suggested by Rosenbach "Wahrend diese letztere einer dauernden Vergrosserung der betreffenden Herzhohle, auch wahrend der Systole, entspricht, ist erstere nur der Ausdruck einer starkeren Fullung und deshalb grosseren Ausdehnung der Hohle wahrend der Diastole. Es handelt sich also in dem einen Falle um eine constante, absolute, in dem anderen um eine relative Erweiterung; der ersteren geht die Hypertrophie voran, der letzteren folgt sie." There is absolutely no indication that infection must precede hypertrophy.

The relationship of the heart size changes to those observed in electrocardiograms has already been discussed; some change was always in evidence though we agree with Herrmann that the changes attributed to left ventricular preponderance in man are not observed. The increased duration of the QRSS group to which attention has been drawn could be accounted for readily by the increased distance the impulses have to travel, whether this increase depends on the larger cavity and a lengthening of the conducting tissue, or on a change in the thickness of the muscle wall.

The figures that have been given for the duration of systole show that this is longer than normal. This change as well as the increase in pulse rate would act to shorten the diastolic period during which regurgitation could occur. Support is, therefore, given to the established clinical belief that a moderately rapid pulse is of benefit in aortic regurgitation, and, however fit, none of our animals have ever developed a really slow pulse. The results are also in agreement with those which Allan (32) has recently obtained in a circulation schema. When failure occurs (experiments $E$ and $F$ ) the duration of systole was still above normal, but was found to be decreasing from the levels that had been maintained previously. Even though some electrocardiograms were taken on animals within a few hours of death, the heart failure could not be predicted from the absolute value of the duration of systole observed, though it was indicated by a decreasing systole/cycle ratio (19).

Some effect of the operation on the auricle was suggested by an immediate and marked increase in both potential and duration of the 
$\mathrm{P}$ wave; further evidence of this was seen at autopsy in thickening of the left auricular wall, which was often quite definite and sometimes the wall of the right ventricle also seemed above normal thickness. No other evidence of back pressure was observed except in experiment $C$. In general the changes observed agree with the theories advanced by Cohnheim and his pupil Rosenbach and by Marey, and we can only claim to have supported their evidence with data obtained by recent methods which were not available to them.

\section{CONCLUSIONS}

1. Chronic aortic regurgitation produced in dogs is followed immediately by a diminution in the size of the heart shadow, though later this shows a gradual increase.

2. The pulse rate is raised immediately as the result of the lesion, but the change is rarely sufficient to account completely for the diminution observed in the heart shadow. Later the pulse rate slows but not sufficiently to account for the increase in the heart shadow. The pulse rate never returns to its previous low level, and however fit the animal becomes, a relatively fast pulse appears to be advantageous.

3. The increase in heart size commences probably within the first week and continues rapidly for a period of 1 to 4 months; from 4 months up to 1 year the change is still detectable, but is quite gradual.

4. Deductions of hypertrophy from measurements of heart size by $\mathrm{x}$-ray are much more accurate if allowance is made for the effect of changes in pulse rate. If this is not done only the grossest changes can be detected, and heart shadows below the normal value may be obtained from hearts, which at autopsy can be shown to be hypertrophied by abnormality of the ratios of left to right ventricle and of the heart weight to body weight.

5. The hypertrophy of the left ventricle is associated with an increase in cavity, which is often more obvious than the thickening of the wall.

6. An initial lengthening of the heart shadow is often noted and attention is drawn to the possibility of the left ventricular cavity being increased initially, even though the total heart shadow was decreased.

7. Hypertrophy does not depend on infection.

8. The electrocardiographic records show consistent changes. The potential of any of the waves, except S, may be increased in any 
lead, but in particular the $Q$ wave may be much increased, and the $\mathrm{S}$ wave is usually decreased in all three leads. The QRS group may become of longer duration, and the lengthening is on the average proportional to the increase in heart size. Systole measured mechanically or electrically is of greater duration than normal, but this lengthening is reduced when failure supervenes. The electrocardiographic changes associated with left ventricular preponderance in man are never seen in our dogs, even when a considerable hypertrophy is known to be present. Both the changes observed in the character of the waves with hypertrophy and the alterations of the same type but of less degree sometimes seen immediately after operation, can possibly be explained as a result of a rotation of the heart.

9. The total lack of symptoms in most cases (except when infection was present) is astonishing, and the ability to do work is often very great, though probably lessened as the result of the operation.

We should like to express our thanks to Dr. R. T. Grant for his examination of the pathological material, and also to Dr. J. A. Eyster* for helpful criticism at the commencement of the work.

\section{BIBLIOGRAPHY}

1. Cohnheim, J: Allgemeine Pathologie. Berlin, 1877.

2. Rosenbach, O: Arch. f. Exp. Path. and Pharm., 1878, ix, 1. Ueber Artificielle Herzklappenfehler.

3. Marey, E. J.: Circulation du Sang. Paris, 1881, p. 674.

4. Tangl, F.: Virchow's Arch. f. Path. Anat., 1889, cxvi, 432. Ueber die Hypertrophie und das Physiologische Wachtsum des Herzens.

5. Hasenfeld and Romberg: Arch. f. Exp. Path. u. Pharm., 1897, 39, $333 . \quad$ Ueber die Reservekraft des Hypertrophischen Herzmunkels und die Bedentung der Diastolischen Erweiterungsfahigkeit des Herzens.

6. Stewart, H. A.: Arch. Int. Med., 1908, i, 102. Experimental and Clinical Investigation of the Pulse and Blood Pressure Changes in Aortic Insufficiency.

7. Stewart, H. A.: Jour. Exp. Med., 1911, xiii, 187. An Experimental Contribution to the Study of Cardiac Hypertrophy.

* Somewhat similar observations have been made by Dr. Eyster and his coworkers both on aortic stenosis and regurgitation, and their experiments have been carried on simultaneously with ours. We are much indebted to them for an exchange of manuscripts and except for accidental causes the two papers would have appeared together. Their results are in some respects different from ours, particularly in that they noted an early cardiac enlargement following operation, and the cause of this discrepancy is not clear. Their paper will appear at an early date. 
8. Stewart, G. N.: Amer. Jour. Physiol., 1921, lviii, 45. Possible Relations of the Weight of the Lungs and other Organs to Body-Weight and Surface Area (in Dogs).

9. MacCallum, W. G.: Johns Hopkins Hosp. Bull., 1906, xvii, 251. On the Teaching of Pathological Physiology, and Johns Hopkins Hosp. Bull., 1911, xxii, 197. The Changes in the Circulation in Aortic Insufficiency.

10. Wiggers, C. J.: Arch. Int. Med., 1915, xvi, 132.

11. Wiggers, C. J.: Circulation in Health and Disease. Second ed., Philadelphia, 1924.

12. Sherrington, C.: Mammalian Physiol. Clarendon Press, 1919, p. 60.

13. Straub, H.: Deut. Med. Wchnschr., 1919, xlv, 676. Ueber Herzerweiterung.

14. Sands, J.: Quart. Jour. Exp. Physiol. (Supp. Vol.), 1923, p. 215. Chronic Aortic Regurgitation in Dogs.

15. Bazett, H. C.: Amer. Jour. Physiol., 1925, lxxii, 201. Further Observations on Experimental Aortic Regurgitation.

16. Hermann, G. R.: Jour. Clin.: Invest., 1925, i, 574. Experimental Heart Disease.

17. Eyster, J. A., and Meek, W. J.: Amer. Jour. Roent., 1920, 1, 471. Instantaneous Radiographs of the Human Heart at Determined Points in the Cardiac Cycle.

18. Eyster, J. A.: Communication to Amer. Physiological Soc., 1926.

19. Bazett, H. C., and Sands J.: Annals of Clinical Medicine (In Press).

20. Külbs: Arch. f. Exp. Path. u. Pharm., 1906, lv, 288. Experimentelles über Herzmuskel und Arbeit.

21. Bazett, H. C.: Amer. Jour. Physiol., 1924, lxx, 550. Factors in the Causation of Differential Blood Pressure.

22. Keller, L.: Pfluger's Arch. f. d. ges. Physiol., 1922, cxcvii, 443 . Über Gipsausgüsse Einiger Saugetierherzen; Zugleich ein Beitrage zur Schlagvolumfrage.

23. Lewis, T.: Heart, 1924, ii, 151. Studies of Capillary Pulsation.

24. Meek, W. J.: Amer. Jour. Physiol., 1925, lxxii, 228. The Effect of Changes in Position of the Heart on the Q.R.S. Complex of the Electrocardiogram.

25. Mines, G. R.: Jour. Physiol., 1913, xlvi, 349. On Dynamic Equilibrium in the Heart.

26. Lewis, T.: Heart, 1925, xii, 209. Conduction in Mammalian Heart.

27. Meek, W. J.: Amer. Jour. Physiol., 1924, lxx, 385. The Effect of Changes in Pulse Rate on Diastolic Heart Size.

28. Meek, W. J., and Wilson, J. A.: Amer. Jour. Physiol., 1925, lxxii, 228. The Effect of Changes in Position of the Heart on the QRS Complex of the Electrocardiogram.

29. Joseph, D. R.: Jour. Exp. Med., 1908, x, 521. The Ratio between the HeartWeight and Body-Weight in Various Animals.

30. Anrep, G. V., and Segall, H. N.: Jour. Physiol., 1926, lxi, 215. The Central and Reflex Regulation of the Heart Rate.

31. Marshall, E. K.: Amer. Jour. Physiol., 1925, lxxii, 192. Cardiac Output.

32. Allan, G. A.: Heart, 1925, xii, 181. Schema of Circulation with Experiments to Determine Additional Load on Apparatus Produced by Conditions Representing Valvular Lesions. 